\title{
molecules
}

ISSN 1420-3049

www.mdpi.com/journal/molecules

Article

\section{Synthesis, Cytotoxicity and Mechanistic Evaluation of 4-Oxoquinoline-3-carboxamide Derivatives: Finding New Potential Anticancer Drugs}

Luana da S. M. Forezi ${ }^{1}$, Nathalia M. C. Tolentino ${ }^{1}$, Alessandra M. T. de Souza ${ }^{2}$, Helena C. Castro ${ }^{3}$, Raquel C. Montenegro ${ }^{4}$, Rafael F. Dantas ${ }^{5}$, Maria E. I. M. Oliveira ${ }^{5}$, Floriano P. Silva, Jr. ${ }^{5}$, Leilane H. Barreto ${ }^{4}$, Rommel M. R. Burbano ${ }^{4}$, Bárbara Abrahim-Vieira ${ }^{2}$, Riethe de Oliveira $^{2}$, Vitor F. Ferreira ${ }^{1}$, Anna C. Cunha ${ }^{1}$, Fernanda da C. S. Boechat ${ }^{1}$ and Maria Cecília B. V. de Souza ${ }^{1, *}$

1 Outeiro de São João Batista, Fluminense FederalUniversity (UFF), s/n, Niterói 24020141, RJ, Brazil

2 Laboratory of Molecular Modeling \& QSAR (ModMolQSAR), Federal University of Rio de Janeiro (UFRJ), Rio de Janeiro 21949-900, RJ, Brazil

3 LABIEMol, Outeiro de São João Batista, Fluminense Federal University, s/n, Niterói 24020-141, RJ, Brazil

4 Institute of Biological Sciences, Federal University of Pará, Av. Augusto Corrêa, n.01 - Guamá, Belém, 66075-110, Pará, Brazil

5 Laboratory of Biochemistry of Proteins and Peptides, Oswaldo Cruz Institute, FIOCRUZ, Rio de Janeiro 21040-900, RJ, Brazil

* Author to whom correspondence should be addressed; E-Mail: gqocica@vm.uff.br; Tel.: +55-21-2629-2138; Fax: +55-21-2629-2144.

Received: 25 March 2014; in revised form: 1 May 2014 / Accepted: 12 May 2014 / Published: 22 May 2014

Abstract: As part of a continuing search for new potential anticancer candidates, we describe the synthesis, cytotoxicity and mechanistic evaluation of a series of 4-oxoquinoline-3-carboxamide derivatives as novel anticancer agents. The inhibitory activity of compounds 10-18 was determined against three cancer cell lines using the MTT colorimetric assay. The screening revealed that derivatives $\mathbf{1 6 b}$ and $\mathbf{1 7 b}$ exhibited significant cytotoxic activity against the gastric cancer cell line but was not active against a normal cell line, in contrast to doxorubicin, a standard chemotherapeutic drug in clinical use. Interestingly, no hemolytical activity was observed when the toxicity of $\mathbf{1 6} \mathbf{b}$ and $\mathbf{1 7} \mathbf{b}$ was tested against blood cells. The in silico and in vitro mechanistic evaluation indicated 
the potential of $\mathbf{1 6 b}$ as a lead for the development of novel anticancer agents against gastric cancer cells.

Keywords: 4-oxoquinoline; carboxamide; heterocycles; anticancer

\section{Introduction}

Currently, most treatments against cancer are multimodal, involving chemotherapy, radiation and surgery to treat tumors. However, due to the present limitations associated with standard chemotherapy, including side effects and acquired tumor resistance, there is an urgent need to discover new anticancer agents with improved therapeutic profiles. Despite these issues, chemotherapy continues to be the most prevalent pharmacological approach for the treatment of cancer [1].

Oxoquinolines are a class of compounds with important biological activities [2-4]. They represent an important group of heterocyclic compounds because of their pharmacological activities against bacterial infections [5].

The mechanism of the antibacterial activity of 4-oxoquinolines involves modulation of prokaryotic type II topoisomerases (DNA gyrase and topoisomerase IV), and they cause cell death by generating high levels of double-stranded DNA breaks. These enzymes are homologous to human type II topoisomerases, which modulate the topological state of the genetic material by passing an intact DNA helix through a transient double stranded break generated in a separate part of DNA. Thus, 4-oxoquinolines may also exhibit anticancer activity through the same mechanism [6-9].

In the last several decades, the described new 4-oxoquinoline derivatives were able to reduce mortality when administered as prophylaxis for infections in cancer patients [6,7,10-13] and with feasible anticancer profile. According to the literature [10], the mechanism of action may be related to the inhibition of mammalian topoisomerase II, which is a target of many antitumor agents. Interestingly, some 4-oxoquinolines show antineoplastic activity as high as etoposide, an anticancer drug.

Some oxoquinoline derivatives and analogues have shown interesting antimitotic profiles (Figure 1) $[14,15]$. Notably, voreloxin $(6)[8,16]$ is an 4-oxoquinoline analogue that shows anticancer activity by intercalating in DNA and affecting topoisomerase II [6,7,10]. Currently, this compound is undergoing pre-clinical evaluation $[8,16]$.

In the continuing search for more selective anticancer agents, many research groups worldwide are conducting research concerning structural modification of the oxoquinolinic core to obtain more potent drugs with fewer side effects. Herein, we report the synthesis, the biological and theoretical evaluations of a series of 4-oxoquinoline derivatives as investigational anticancer agents and explore the mechanism of action of these molecules.

\section{Results and Discussion}

\subsection{Chemistry}

As shown in the Scheme 1, the derivatives were synthesized using a three-step procedure that involves the condensation of anilines 7 with diethyl ethoxymethylenemalonate (EMME)in refluxing 
ethanol followed by thermal cyclization of the aniline acrylate intermediates $\mathbf{8}$, according to GouldJacobs methodology [17-21]. A nucleophilic substitution reaction between oxoquinolines 9 and the appropriate amines in diphenyl ether as solvent affords the respective carboxamides 10-18 (Table 1) in 30\%-98\% yields. Their structures (new compounds) were confirmed by IR, NMR and mass spectroscopy. The HPLC analysis of $\mathbf{1 6} \mathbf{b}$ and $\mathbf{1 7 b}$ was also performed.

Figure 1. Structures of voreloxin (6) and several oxoquinoline derivatives 1-5 with anticancer activity.

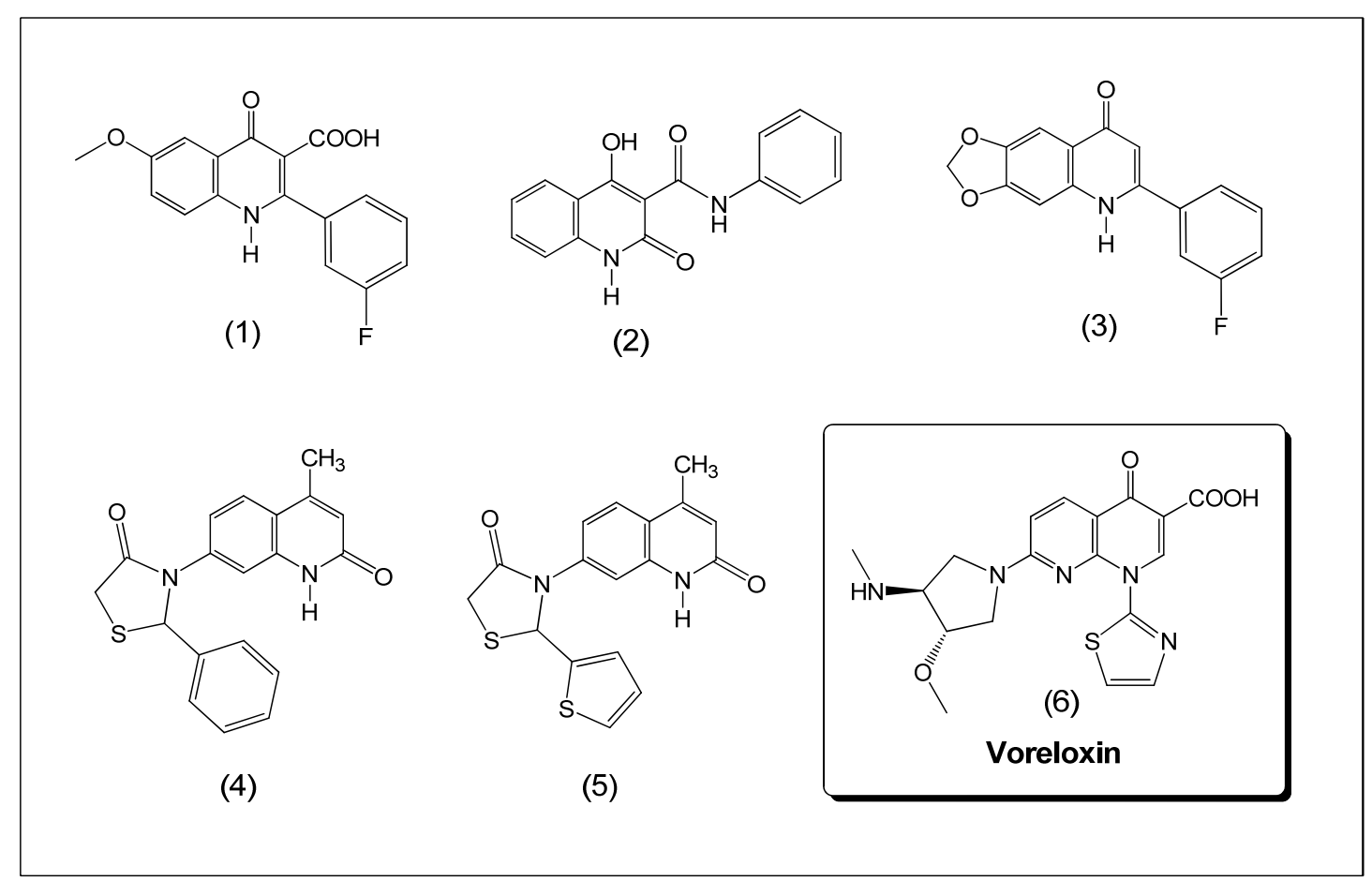

Scheme 1. Synthesis of 4-oxoquinolines 10-18.

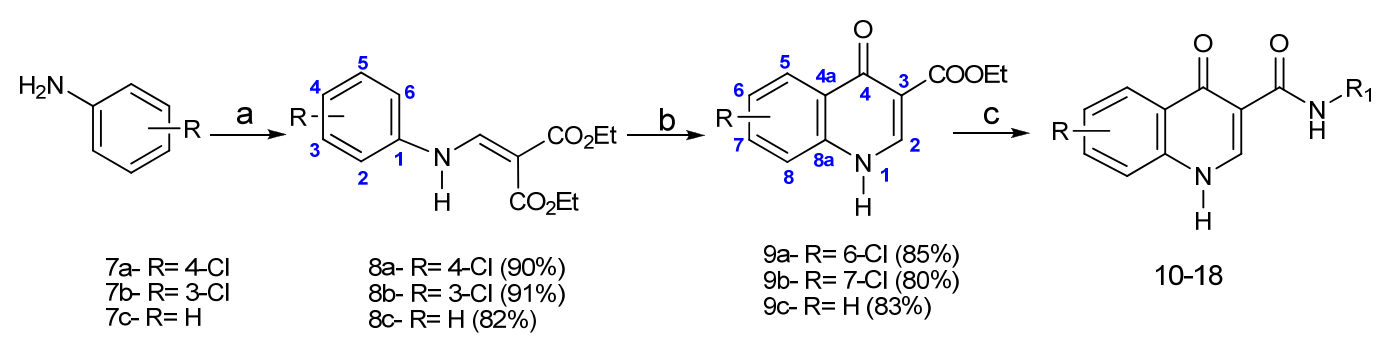

Reagents and conditions: (a) diethyl ethoxymethylenemalonate (EMME), ethanol, reflux; (b) diphenyl ether, reflux; (c) diphenyl ether, amine, $210{ }^{\circ} \mathrm{C}$.

\subsection{Evaluation of Anticancer Activity in Vitro}

All oxoquinolinecarboxamides 10-18 were evaluated in vitro against three cancer cell lines from different origins: colon (HCT-116), stomach (ACP03) and breast (MDAMB-231). The toxicological profiles of the active derivatives $\left(\mathrm{IC}_{50}<20 \mu \mathrm{M}\right.$ ) were also evaluated by testing on a normal fibroblast cell line (MRC-5) and erythrocytes. The concentration that inhibits $50 \%$ of cell growth $\left(\mathrm{IC}_{50}\right)$ was 
reported in $\mu \mathrm{M}$, and the hemolytic potential is expressed in $\mu \mathrm{g} / \mathrm{mL}$ (Table 2). Finally, a total of 24 derivatives were evaluated, and doxorubicin [22] was used as a positive control.

Table 1. Yields and melting points of 4-oxoquinolines 10-18.

\begin{tabular}{|c|c|c|c|c|}
\hline Derivative & $\mathbf{R}$ & $\mathbf{R}_{1}$ & Yield $(\%)$ & MP $\left({ }^{\circ} \mathrm{C}\right)$ \\
\hline $10 \mathrm{a}$ & $\mathrm{H}$ & & 96 & $244-246$ \\
\hline $10 \mathrm{~b}$ & $6-\mathrm{Cl}$ & & 85 & $262-263$ \\
\hline $10 \mathrm{c}$ & 7-Cl & & 79 & $220-221$ \\
\hline $11 \mathrm{a}$ & $\mathrm{H}$ & & 30 & 209-212 \\
\hline $11 \mathrm{~b}$ & $6-\mathrm{Cl}$ & & 58 & $140-142$ \\
\hline $11 \mathrm{c}$ & 7-Cl & & 75 & $140-141$ \\
\hline $12 a$ & $\mathrm{H}$ & & 96 & $>300$ \\
\hline $12 \mathrm{~b}$ & $6-\mathrm{Cl}$ & & 98 & $>300$ \\
\hline $13 a$ & $\mathrm{H}$ & & 94 & $>300$ \\
\hline $13 b$ & 7-Cl & & 80 & $>300$ \\
\hline $14 a$ & $\mathrm{H}$ & & 86 & $>300$ \\
\hline $14 b$ & $7-\mathrm{Cl}$ & & 87 & $270-273$ \\
\hline $15 a$ & $\mathrm{H}$ & & 79 & $>300$ \\
\hline $15 b$ & $6-\mathrm{Cl}$ & & 85 & $>300$ \\
\hline $15 \mathrm{c}$ & 7-Cl & & 83 & $>300$ \\
\hline $16 a$ & $\mathrm{H}$ & & 94 & $>300$ \\
\hline $16 \mathrm{~b}$ & $6-\mathrm{Cl}$ & & 96 & $>300$ \\
\hline $16 \mathrm{c}$ & $7-\mathrm{Cl}$ & & 86 & $>300$ \\
\hline $17 \mathbf{a}$ & $\mathrm{H}$ & & 66 & $>300$ \\
\hline $17 \mathrm{~b}$ & $6-\mathrm{Cl}$ & & 98 & $>300$ \\
\hline $17 \mathrm{c}$ & 7-Cl & & 63 & $>300$ \\
\hline $18 \mathrm{a}$ & $\mathrm{H}$ & & 57 & $250-251$ \\
\hline $18 b$ & $6-\mathrm{Cl}$ & & 44 & $256-258$ \\
\hline $18 \mathrm{c}$ & 7- $\mathrm{Cl}$ & & 45 & $261-262$ \\
\hline
\end{tabular}

Derivatives $\mathbf{1 6 b}$ and $\mathbf{1 7 b}$ displayed cytotoxicity against the gastric cancer cell line, with $\mathrm{IC}_{50}$ values of 1.92 and $5.18 \mu \mathrm{M}$, respectively (Table 2). However, in normal fibroblasts, they did not display cytotoxicity at $20 \mu \mathrm{M}$. Although the $\mathrm{IC}_{50}$ of doxorubicin was lower than those of $\mathbf{1 6 \mathbf { b }}$ and $\mathbf{1 7} \mathbf{b}$, these derivatives were ten times more selective against cancer cells than to normal cells (Figure 2); doxorubicin shows no selectivity between cancer and normal cells (Table 2 and Figure 2).

Hemolytic activity is an acute toxic effect that must be analyzed when evaluating any new oral or intravenous drug. Therefore, we performed a hemolytic assay in mice erythrocytes to evaluate nonspecific damage to plasma membranes. Importantly, no hemolytic activity $\left(\mathrm{EC}_{50}>200 \mu \mathrm{g} / \mathrm{mL}\right)$ was observed for any of the tested derivatives, suggesting that the cytotoxicity against cancer cell lines is not related to membrane damage. 
Table 2. Cytotoxic activity of 10-18 on cancer cell lines (ACP-03, HCT-116 and MDAMB-231), a normal fibroblast cell line (MRC-5) and erythrocytes (to measure hemolysis).

\begin{tabular}{|c|c|c|c|c|c|}
\hline Derivatives & & & $\mathrm{IC}_{50} \mu \mathrm{M}$ & & $\begin{array}{c}\text { Hemolysis } \\
(\mu \mathrm{g} / \mathrm{mL})\end{array}$ \\
\hline & ACP-03 & HCT-116 & MDAMB231 & MRC5 & \\
\hline $10 \mathrm{a}$ & $>10$ & $>10$ & $>10$ & ND & $>200$ \\
\hline $10 \mathrm{~b}$ & $>10$ & $>10$ & $>10$ & ND & $>200$ \\
\hline $10 \mathrm{c}$ & $>10$ & $>10$ & $>10$ & ND & $>200$ \\
\hline $11 \mathrm{a}$ & $>10$ & $>10$ & $>10$ & ND & $>200$ \\
\hline $11 \mathrm{~b}$ & $>10$ & $>10$ & $>10$ & ND & $>200$ \\
\hline $11 \mathrm{c}$ & $>10$ & $>10$ & $>10$ & ND & $>200$ \\
\hline $12 \mathrm{a}$ & $>10$ & $>10$ & $>10$ & ND & $>200$ \\
\hline $12 b$ & $>10$ & $>10$ & $>10$ & ND & $>200$ \\
\hline $13 a$ & $>10$ & $>10$ & $>10$ & ND & $>200$ \\
\hline $13 b$ & $>10$ & $>10$ & $>10$ & ND & $>200$ \\
\hline $14 a$ & $>10$ & $>10$ & $>10$ & ND & $>200$ \\
\hline $14 b$ & $>10$ & $>10$ & $>10$ & ND & $>200$ \\
\hline $15 a$ & $>10$ & $>10$ & $>10$ & ND & $>200$ \\
\hline $15 b$ & $>10$ & $>10$ & $>10$ & ND & $>200$ \\
\hline $15 \mathrm{c}$ & $>10$ & $>10$ & $>10$ & ND & $>200$ \\
\hline $16 a$ & $>10$ & $>10$ & $>10$ & ND & $>200$ \\
\hline $16 \mathrm{~b}$ & $1.92(1.39-2.66)$ & $>10$ & $>10$ & $>\mathbf{2 0}$ & $>\mathbf{2 0 0}$ \\
\hline $16 \mathrm{c}$ & $>10$ & $>10$ & $>10$ & ND & $>200$ \\
\hline $17 \mathbf{a}$ & $>10$ & $>10$ & $>10$ & ND & $>200$ \\
\hline $17 b$ & $5.18(3.61-7.45)$ & $>10$ & $>10$ & $>\mathbf{2 0}$ & $>\mathbf{2 0 0}$ \\
\hline $17 \mathrm{c}$ & $>10$ & $>10$ & $>10$ & ND & $>200$ \\
\hline $18 \mathbf{a}$ & $>10$ & $>10$ & $>10$ & ND & $>200$ \\
\hline $18 \mathrm{~b}$ & $>10$ & $>10$ & $>10$ & ND & $>200$ \\
\hline $18 \mathrm{c}$ & $>10$ & $>10$ & $>10$ & ND & $>200$ \\
\hline DOXORUBICIN & $0.274(0.22-0.33)$ & $0.1(0.047-0.28)$ & $0.43(0.36-0.52)$ & $0.2(0.16-0.25)$ & $>200$ \\
\hline
\end{tabular}

Data are presented as the $\mathrm{IC}_{50}$ values, and $95 \%$ confidence intervals were obtained by nonlinear regression for all cell lines (gastric (ACP03), colon (HCT-116), breast (MDAMB231), and normal human fetal lung fibroblast (MRC5)) from three independent experiments. Doxorubicin (Dox) was used as the positive control. Experiments were performed in triplicate. $\mathrm{IC}_{50}=$ concentrations that result in $50 \%$ inhibition of cell growth, in $\mu \mathrm{M}$. ND—Not determined.

\subsection{In Silico Mechanism Analysis: Topoisomerase II as a Feasible Target}

Previous studies have shown that voreloxin $[8,16]$, a first-in-class cytotoxic 4-oxoquinoline analogue, intercalates into DNA and inhibits topoisomerase II [6,7]. Based on these results, we investigated the feasibility of this mechanism by docking the most actives derivatives $\mathbf{1 6} \mathbf{b}$ and $\mathbf{1 7} \mathbf{b}$, into the DNA binding site of topoisomerase II (Figure 3). 
Figure 2. Comparison of the $\mathrm{IC}_{50}$ values of derivatives against a gastric cancer cell line (ACP-03) and normal fibroblast cell line (MRC-5).

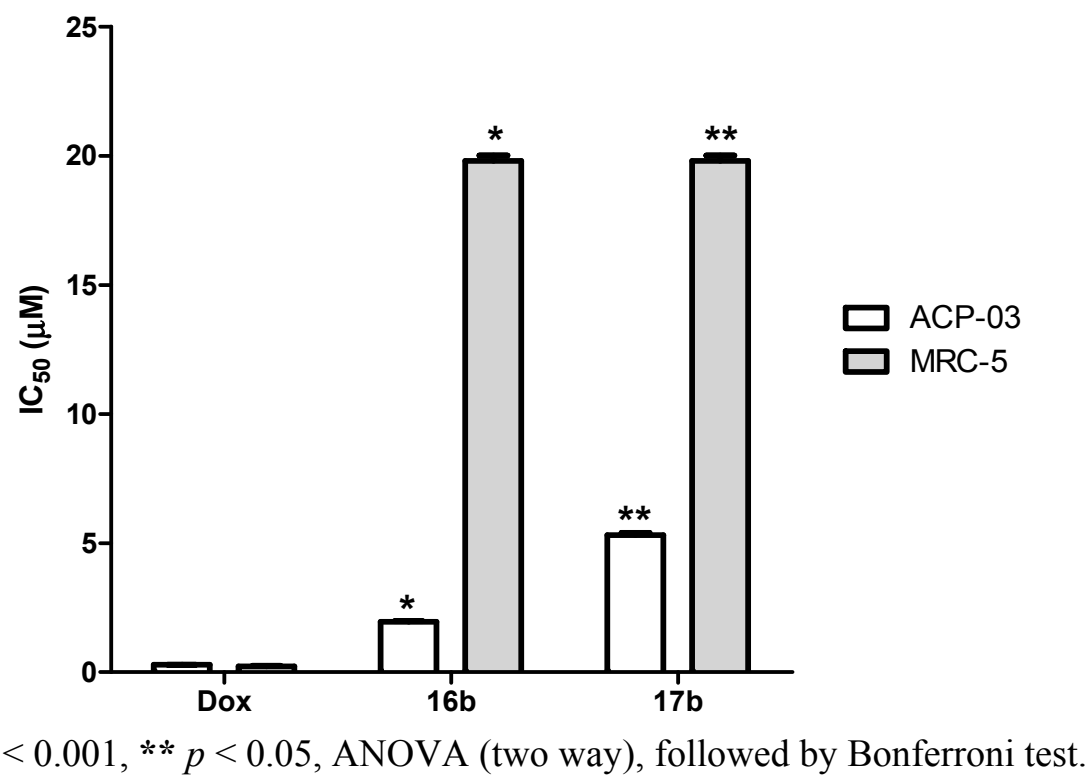

The validity of the docking accuracy was evaluated by redocking using the crystal structure of topoisomerase II (PDB ID: 3QX3 complexed with etoposide, an inhibitor) as described in the experimental section. The reliability of the docking protocol was first checked by comparing the best docking position of the inhibitor with its crystal structure that was obtained using the GOLD program.

The comparison of the redocking results with the co-crystallized conformation was performed using the program Pymol. The in silico analysis revealed a conformation similar to the crystallized structure with a root mean square deviation (RMSD) of $0.14 \AA$. These data supported the hypothesis that the experimental binding mode could be accurately reproduced using this protocol.

The molecular docking data showed that the carbonyl group in the heterocyclic ring of $\mathbf{1 6 b}$ interacts via a hydrogen bond with the GLN778 residue of the enzyme (O-O $3.9 \AA$ ) (Figure 3A) and the same ring of $\mathbf{1 7 b}$ interacts (O-N $2.8 \AA$ ). Similarly, hydrogen bond interactions were also observed between the inhibitor and cytosine $(-1)$, guanine $(+5)$ and thymine $(+1)$ at distances of 3.5, 4.1 and $5.3 \AA$, respectively for $\mathbf{1 6 b}$, while for $\mathbf{1 7 b}$ were $2.7,4.0$ and $5.2 \AA$ between cytosine $(-1)$, guanine $(+5)$, adenosine $(+4)$, respectively. The literature reports that etoposide interacts with the enzyme and with DNA [23]. Interestingly, whereas etoposide interacts through extensive contacts, $\mathbf{1 6} \mathbf{b}$ and $\mathbf{1 7 b}$ have a smaller molecular volume and interacts only with the GLN778 residue of the enzyme. This interaction seems to contribute to the stabilization of the complex formed by this ligand and the topoisomerase II. Similar to etoposide [24], these derivatives bind between the base pairs showed, possibly preventing their stacking and consequently blocking the re-ligation of the cleaved phosphodiester bond between the nucleotides. However, 17b showed no parallel position interactions when compared with $\mathbf{1 6 b}$, probable due to the effect of ortho-chlorine substitution. Thereat, weak interactions were observed, supporting its lower activity than $\mathbf{1 6 b}$. 
Figure 3. Molecular docking of $\mathbf{1 6 b}(\mathbf{A})$ and $\mathbf{1 7 b}(\mathbf{B})$ in the topoisomerase II binding site: The cartoon-and-stick representation shows the insertion of $\mathbf{1 6} \mathbf{b}$ (in red) and $\mathbf{1 7} \mathbf{b}$ (in pink) as well as the hydrogen bonds (in green) between the GLN778 residue of the enzyme (in yellow) and the nucleotides(Adn, adenosine; Cyt, cytosine; Thy, thymine; Gua, guanine).

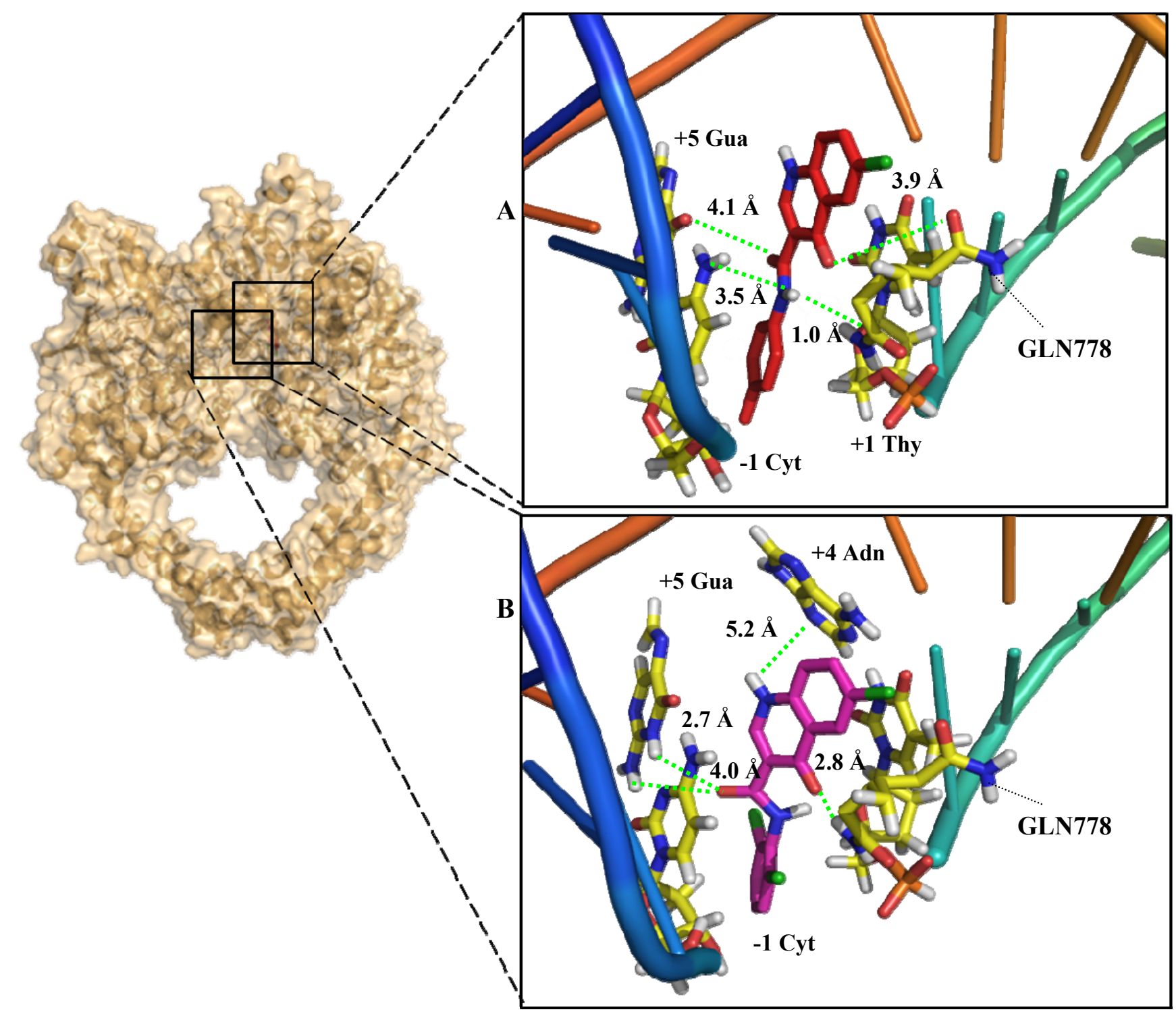

\subsection{In Vitro Mechanistic Evaluation: Topoisomerase II as a Target}

To confirm the theoretical data, we performed a topoisomerase II relaxation assay in the presence of 16b and 17b (Figure 4). The gel bands represent the different conformational forms of pRYG after the reaction catalyzed by topoisomerase II alone (lanes E, F and G) or pre-incubated with $100 \mu \mathrm{M} 16$ b, 17b or VP-16 (etoposide) (lanes A, B and H). The electrophoresis conditions of this experiment, specifically the absence of ethidium bromide, allowed the supercoiled (SC) form of pRYG to migrate as a single band on the gel. The addition of topoisomerase II unwinds the SC-producing topoisomers $(\mathrm{Rn})$ and is shown in the gel as discrete bands that migrate slower than SC. In the presence of $\mathbf{1 6 b}, \mathbf{1 7} \mathbf{b}$ or VP-16, only the SC band is observed, which indicates topoisomerase inhibition. These results support in the in silico docking evaluation pointing this enzyme a target for these new derivatives. 
Figure 4. Effects of $\mathbf{1 6 b}$ and $\mathbf{1 7 b}$ on the inhibition of supercoiled DNA relaxation promoted by topoisomerase II. Supercoiled DNA (pRYG, $200 \mathrm{ng}$ ) was incubated with topoisomerase II $(10 \mathrm{U})$ in the presence of the derivatives and then analyzed on an agarose gel without ethidium bromide. Lanes A and B, supercoiled DNA incubated with topoisomerase II and $100 \mu \mathrm{M}$ of compounds $\mathbf{1 6 b}$ or $\mathbf{1 7 b}$, respectively; lane $\mathrm{C}$, ladder; lane $\mathrm{D}$, supercoiled DNA without enzyme; lanes E,F,G, supercoiled DNA incubated with enzyme alone; lane $\mathrm{H}$, supercoiled DNA with topoisomerase II in the presence of $100 \mu \mathrm{M}$ VP-16. The arrow indicates the supercoiled (SC) DNA band, and the brackets indicate the topoisomer bands $(\mathrm{Rn})$.

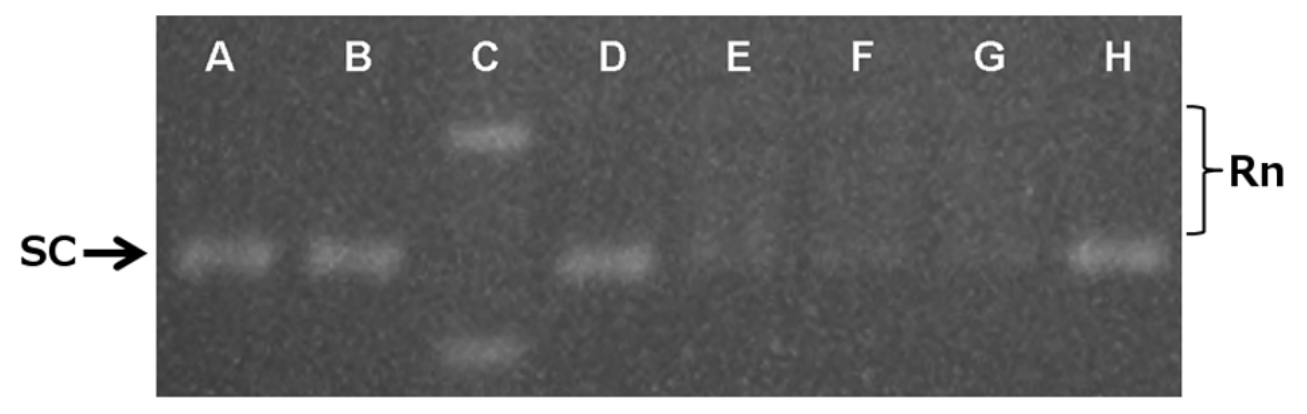

Figure 5. Comparison of $\mathbf{1 6 b}$ and $\mathbf{1 7 b}$ with anticancer marketed drugs, cisplatin and fluorouracil, (A) "Druglikeness"; and (B) in silico toxicity values calculated by using the Osiris Program and the physico-chemical parameters considering Lipinski's rule-of-five paradigm.

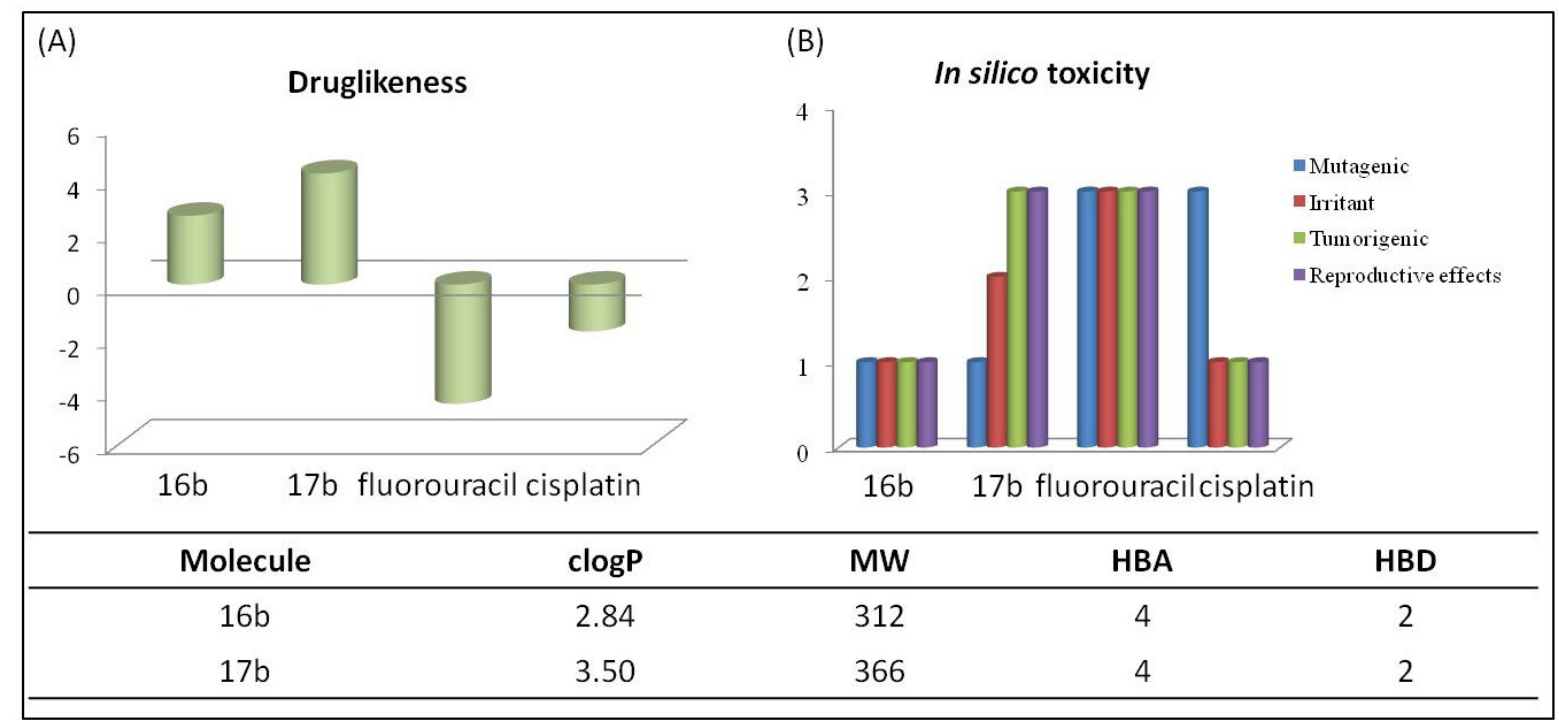

\subsection{In Silico Pharmacokinetic Analysis}

In this work we also assessed $\mathbf{1 6 b}$ and $\mathbf{1 7 b}$ pharmacokinetic properties by using in silico evaluation. Because significant absorption is necessary for oral administration, we analyzed this derivative according to the "rule-of-five" developed by Lipinski and co-workers [25].The rule-of-five indicates the theoretical potential of a chemical compound to exhibit satisfactory oral bioavailability. The rule states that the most "druglike" molecules have a clog $P \leq 5$, molecular weight $(\mathrm{MW}) \leq 500$, number of 
hydrogen bond acceptors $(\mathrm{HBA}) \leq 10$ and number of hydrogen bond donors $(\mathrm{HBD}) \leq 5$. Molecules violating more than one of these rules may show a low bioavailability profile. The results showed that compound $\mathbf{1 6 b}$ and $\mathbf{1 7 b}$ fulfilled the Lipinski "rule-of-five" (Figure 5). The "druglikeness test" calculation that evaluates the profile of the derivative as a drug, showed $\mathbf{1 6 b}$ and $\mathbf{1 7 b}$ with the better values than marketed drugs such as cisplatin and fluorouracil. Finally, according to our in silico toxicity evaluation of tumorigenic, irritant, mutagenic and reproductive effects, and compound 16b showed low profile for these toxicity effects (Figure 5). It is important to note that the toxicity predicted herein neither is a fully reliable toxicity prediction nor guarantees that these compounds are completely free of any toxic effects. However, it reinforced the promising profile of $16 \mathrm{~b}$ for further experimental evaluation.

\section{Experimental}

\subsection{General Information}

${ }^{1} \mathrm{H}-\mathrm{NMR}$ spectra were recorded on a Varian Unity Plus 300 spectrometer operating at $200.00 \mathrm{MHz}$, 300.00 MHz or $500.00 \mathrm{MHz}\left({ }^{1} \mathrm{H}\right)$ and $50.0 \mathrm{MHz}, 75.0 \mathrm{MHz}$ or $125.0 \mathrm{MHz}\left({ }^{13} \mathrm{C}\right)$, using $\mathrm{CDCl}_{3}$ or DMSO- $d_{6}$ as the solvent. Chemical shifts were reported in parts per million (ppm) relative to the internal standard tetramethylsilane (TMS). Signals were designated as follows: brs, broad singlet; s, singlet; d, doublet; dd, doublet of doublets; t, triplet; q, quartet; m, multiplet. Hydrogen and carbon NMR spectra were typically obtained at room temperature. The two-dimensional experiments were acquired using standard Varian Associates automated programs for data acquisition and processing. The IR spectra were recorded on a Perkin-Elmer FT-IR 1600 spectrometer using potassium bromide pellets, and frequencies were expressed in $\mathrm{cm}^{-1}$. Mass spectra were obtained with ESI (MICRO-TOF BRUKER DALTONICS). The HPLC analysis was performed using a Dionex Ultimate 3000 HPLC System with a DAD Detector. Analyteevaluation was carried out with an Acclaim $120 \mathrm{C}_{18}$ column $(3 \mu \mathrm{m}$, $150 \times 4.6 \mathrm{~mm}$ ), provided by Dionex (Sunnyvale, CA, USA).The melting points were determined with a Fisher-Johns apparatus and were uncorrected. All solvents and reagents were purchased from commercial sources: Sigma-Aldrich Brazil (São Paulo, Brazil), Acros Organics (Geel, Belgium) and Tedia Brazil (Rio de Janeiro, Brazil).

\subsection{Synthesis}

\subsubsection{General Procedure for the Synthesis of Anilinomethylenemalonates $\mathbf{8 a}-\mathbf{c}$}

A solution of the appropriate aniline $(100 \mathrm{mmol})$, and diethyl ethoxymethylenemalonate $(20.4 \mathrm{~mL}$, $100 \mathrm{mmol}$ ) was heated under reflux for $3 \mathrm{~h}$. The mixture was allowed to cool and then was poured into ice-cold water $(100 \mathrm{~g})$. The precipitate was collected by filtration and recrystallized from hexane to give derivatives $\mathbf{8 a}-\mathbf{c}[20,26,27]$.

Diethyl 4-chloroanilinomethylenemalonate (8a): yield: $22.4 \mathrm{~g}(90 \%)$ as white crystals; m.p.: $80-81{ }^{\circ} \mathrm{C}$; ${ }^{1} \mathrm{H}-\mathrm{NMR}\left(200.00 \mathrm{MHz}, \mathrm{CDCl}_{3}\right) \delta(\mathrm{ppm}): 11.01(1 \mathrm{H}, \mathrm{d}, J=13.5 \mathrm{~Hz}, \mathrm{~N}-H), 8.46(1 \mathrm{H}, \mathrm{d}, J=13.5 \mathrm{~Hz}$, H- $\beta$ ), 7.37-7.31 (2H, m, H-2 and H-6), 7.11-7.04 (2H, m, H-3 and H-5), 4.32 (2H, q, $J=7.2$ Hz, 
$\left.\mathrm{OCH}_{2} \mathrm{CH}_{3}\right), 4.26\left(2 \mathrm{H}, \mathrm{q}, J=7.2 \mathrm{~Hz}, \mathrm{OCH}_{2} \mathrm{CH}_{3}\right), 1.39\left(3 \mathrm{H}, \mathrm{t}, J=7.2 \mathrm{~Hz}, \mathrm{OCH}_{2} \mathrm{CH}_{3}\right), 1.34(3 \mathrm{H}, \mathrm{t}$, $\left.J=7.2 \mathrm{~Hz}, \mathrm{OCH}_{2} \mathrm{CH}_{3}\right)$; IR $(\mathrm{KBr}) v\left(\mathrm{~cm}^{-1}\right): 1721$ and $1675(\mathrm{C}=\mathrm{O}), 1262(\mathrm{C}-\mathrm{O})$.

Diethyl 3-chloroanilinomethylenemalonate (8b): yield: $22.6 \mathrm{~g}(91 \%)$ as white crystals; m.p.: $57-58{ }^{\circ} \mathrm{C}$; ${ }^{1} \mathrm{H}-\mathrm{NMR}\left(200.00 \mathrm{MHz}, \mathrm{CDCl}_{3}\right) \delta(\mathrm{ppm}): 10.99(1 \mathrm{H}, \mathrm{d}, J=12.9 \mathrm{~Hz}, \mathrm{~N}-H), 8.45(1 \mathrm{H}, \mathrm{d}, J=13.5 \mathrm{~Hz}$, $\mathrm{H}-\beta), 7.10(1 \mathrm{H}, \mathrm{dd}, J=2.1$ and $0.9 \mathrm{~Hz}, \mathrm{H}-2), 7.12-7.15(1 \mathrm{H}, \mathrm{m}, \mathrm{H}-4), 7.30(1 \mathrm{H}, \mathrm{t}, J=8.1 \mathrm{~Hz}, \mathrm{H}-5), 7.01$ $(1 \mathrm{H}$, ddd, $J=8.1,2.1$ and $1.2 \mathrm{~Hz}, \mathrm{H}-6), 4.31\left(2 \mathrm{H}, \mathrm{q}, J=7.2 \mathrm{~Hz}, \mathrm{OCH}_{2} \mathrm{CH}_{3}\right), 4.25(2 \mathrm{H}, \mathrm{q}, J=7.2 \mathrm{~Hz}$, $\left.\mathrm{OCH}_{2} \mathrm{CH}_{3}\right), 1.38\left(3 \mathrm{H}, \mathrm{t}, J=7.2 \mathrm{~Hz}, \mathrm{OCH}_{2} \mathrm{CH}_{3}\right), 1.33\left(3 \mathrm{H}, \mathrm{t}, J=7.2 \mathrm{~Hz}, \mathrm{OCH}_{2} \mathrm{CH}_{3}\right)$; IR $(\mathrm{KBr}) v\left(\mathrm{~cm}^{-1}\right)$ : 1713 and $1688(\mathrm{C}=\mathrm{O}), 1256(\mathrm{C}-\mathrm{O})$.

Diethyl anilinomethylenemalonate (8c): yield: $24.8 \mathrm{~g}(82 \%)$ as white crystals; m.p.: $46-48{ }^{\circ} \mathrm{C}$; ${ }^{1} \mathrm{H}-\mathrm{NMR}\left(200.00 \mathrm{MHz}, \mathrm{CDCl}_{3}\right) \delta(\mathrm{ppm}): 11.21(1 \mathrm{H}, \mathrm{d}, J=13.2 \mathrm{~Hz}, \mathrm{~N}-H), 8.51(1 \mathrm{H}, \mathrm{d}, J=13.5 \mathrm{~Hz}$, $\mathrm{H}-\beta), 7.90-7.20(5 \mathrm{H}, \mathrm{m}, \mathrm{Ph}), 4.32\left(2 \mathrm{H}, \mathrm{q}, J=7.2 \mathrm{~Hz}, \mathrm{OCH}_{2} \mathrm{CH}_{3}\right), 4.25\left(2 \mathrm{H}, \mathrm{q}, J=7.2 \mathrm{~Hz}, \mathrm{OCH}_{2} \mathrm{CH}_{3}\right)$, $1.38\left(3 \mathrm{H}, \mathrm{t}, J=7.2 \mathrm{~Hz}, \mathrm{OCH}_{2} \mathrm{CH}_{3}\right), 1.33\left(3 \mathrm{H}, \mathrm{t}, J=7.2 \mathrm{~Hz}, \mathrm{OCH}_{2} \mathrm{CH}_{3}\right)$; IR $(\mathrm{KBr}) v\left(\mathrm{~cm}^{-1}\right): 1718$ and $1675(\mathrm{C}=\mathrm{O}), 1261(\mathrm{C}-\mathrm{O})$.

\subsubsection{General Procedure for the Synthesis of Oxoquinolines 9a-c}

Anilinomethylenemalonates $\mathbf{8 a}-\mathbf{c} \quad(3 \mathrm{~g}, 10.83 \mathrm{mmol})$ were refluxed for $30 \mathrm{~min}$ in diphenyl ether $(30 \mathrm{~mL})$, leading to crudeoxoquinolines $\mathbf{9 a}-\mathbf{c}$ which were recrystallized from dimethylformamide [20,21,26,27].

3-Carbethoxy-6-chloro-1,4-dihydro-4-oxoquinoline (9a): yield: $2.1 \mathrm{~g}(85 \%)$ as white crystals; m.p.: 295-296 ${ }^{\circ} \mathrm{C} ;{ }^{1} \mathrm{H}-\mathrm{NMR}\left(300.00 \mathrm{MHz}, \mathrm{DMSO}-d_{6}\right) \delta(\mathrm{ppm}): 8.65(1 \mathrm{H}, \mathrm{s}, \mathrm{H}-2), 8.22(1 \mathrm{H}, \mathrm{d}, J=2.4 \mathrm{~Hz}, \mathrm{H}-5)$, $7.85(1 \mathrm{H}, \mathrm{dd}, J=9,0$ and $2.4 \mathrm{~Hz}, \mathrm{H}-7), 7.78(1 \mathrm{H}, \mathrm{d}, J=8.7 \mathrm{~Hz}, \mathrm{H}-8), 4.36(2 \mathrm{H}, \mathrm{q}, J=6.9 \mathrm{~Hz}$, $\left.\mathrm{OCH}_{2} \mathrm{CH}_{3}\right), 1.42\left(3 \mathrm{H}, \mathrm{t}, J=6.9 \mathrm{~Hz}, \mathrm{OCH}_{2} \mathrm{CH}_{3}\right)$; IR $(\mathrm{KBr}) v\left(\mathrm{~cm}^{-1}\right): 3300-2800(\mathrm{OH} / \mathrm{NH}), 1688(\mathrm{C}=\mathrm{O})$.

3-Carbethoxy-7-chloro-1,4-dihydro-4-oxoquinoline (9b): yield: $2.0 \mathrm{~g}(80 \%)$ as white crystals; m.p.: 293-294 ${ }^{\circ} \mathrm{C} ;{ }^{1} \mathrm{H}-\mathrm{NMR}\left(300.00 \mathrm{MHz}, \mathrm{DMSO}-d_{6}\right) \delta(\mathrm{ppm}): 8.71(1 \mathrm{H}, \mathrm{s}, \mathrm{H}-2), 8.26(1 \mathrm{H}, \mathrm{d}, J=8.7 \mathrm{~Hz}, \mathrm{H}-5)$, $7.59(1 \mathrm{H}, \mathrm{dd}, J=9.0$ and $2.1 \mathrm{~Hz}, \mathrm{H}-6), 7.79(1 \mathrm{H}, \mathrm{d}, J=2.1 \mathrm{~Hz}, \mathrm{H}-8), 4.33(2 \mathrm{H}, \mathrm{q}, J=6.9 \mathrm{~Hz}$, $\left.\mathrm{OCH}_{2} \mathrm{CH}_{3}\right), 1.39\left(3 \mathrm{H}, \mathrm{t}, J=6.9 \mathrm{~Hz}, \mathrm{OCH}_{2} \mathrm{CH}_{3}\right)$; IR $(\mathrm{KBr}) v\left(\mathrm{~cm}^{-1}\right): 3300-2800(\mathrm{OH} / \mathrm{NH}), 1690(\mathrm{C}=\mathrm{O})$.

3-Carbethoxy-1,4-dihydro-4-oxoquinoline (9c): yield: $2.1 \mathrm{~g}(83 \%)$ as white crystals; m.p.: 268-269 ${ }^{\circ} \mathrm{C}$; ${ }^{1} \mathrm{H}-\mathrm{NMR}\left(300.00 \mathrm{MHz}, \mathrm{DMSO}-d_{6}\right) \delta(\mathrm{ppm}): 8.65(1 \mathrm{H}, \mathrm{s}, \mathrm{H}-2), 8.22(1 \mathrm{H}, \mathrm{d}, J=2.4 \mathrm{~Hz}, \mathrm{H}-5)$, $7.85(1 \mathrm{H}, \mathrm{dd}, J=9.0$ and $2.4 \mathrm{~Hz}, \mathrm{H}-7), 7.78(1 \mathrm{H}, \mathrm{d}, J=8.7 \mathrm{~Hz}, \mathrm{H}-8), 7.49\left(1 \mathrm{H}, \mathrm{m}, \mathrm{H}_{6}\right), 4.36(2 \mathrm{H}, \mathrm{q}$, $\left.J=6.9 \mathrm{~Hz}, \mathrm{OCH}_{2} \mathrm{CH}_{3}\right), 1.42\left(3 \mathrm{H}, \mathrm{t}, J=6.9 \mathrm{~Hz}, \mathrm{OCH}_{2} \mathrm{CH}_{3}\right)$; IR $(\mathrm{KBr}) v\left(\mathrm{~cm}^{-1}\right): 3300-2800(\mathrm{OH} / \mathrm{NH})$, $1695(\mathrm{C}=\mathrm{O})$.

\subsubsection{General Procedure for the Synthesis of Oxoquinolines 10-18}

Oxoquinolines $9 \mathbf{a}-\mathbf{c}(8 \mathrm{mmol})$ were reacted with the appropriate amine $(8 \mathrm{mmol})$ in diphenyl ether $(30 \mathrm{~mL})$ at $210^{\circ} \mathrm{C}$ under magnetic stirring for $1 \mathrm{~h}$. The resulting mixture was poured into petroleum ether. The obtained solid was filtered and recrystallized from dichloromethane/petroleum ether (1/1) to yield the derivatives listed below [28-30]. 
4-Oxo-N'-(4-chlorobenzyl)-1,4-dihydroquinoline-3-carboxamide (10a): yield: $1.4 \mathrm{~g}(96 \%)$ as a light brown solid; m.p.: $244-246{ }^{\circ} \mathrm{C}$; ${ }^{1} \mathrm{H}-\mathrm{NMR}\left(500.00 \mathrm{MHz}, \mathrm{DMSO}-d_{6}\right) \delta(\mathrm{ppm}): 10.43(1 \mathrm{H}, \mathrm{t}, J=5.9 \mathrm{~Hz}$, $\mathrm{C}=\mathrm{ONH}), 8.75(1 \mathrm{H}, \mathrm{s}, \mathrm{H}-2), 8.26(1 \mathrm{H}, \mathrm{dd}, J=8.5$ and $0.9 \mathrm{~Hz}, \mathrm{H}-5), 7.77(1 \mathrm{H}, \mathrm{ddd}, J=8.3,6.8$ and $1.5 \mathrm{~Hz}, \mathrm{H}-7), 7.69(1 \mathrm{H}, \mathrm{dd}, J=8.3$ and $0.7 \mathrm{~Hz}, \mathrm{H}-8), 7.48(1 \mathrm{H}, \mathrm{ddd}, J=8.1,6.8$ and $1.3 \mathrm{~Hz}, \mathrm{H}-6)$, 7.42-7.34 (4H, m, H-2', H-3', H-5' and H-6'), $4.56\left(2 \mathrm{H}, \mathrm{d}, J=6.0 \mathrm{~Hz}, \mathrm{NHCH}_{2}\right) ;{ }^{13} \mathrm{C}-\mathrm{NMR}(125.0 \mathrm{MHz}$, DMSO- $\left.d_{6}\right) \delta$ (ppm): 176.0, 164.5, 143.6, 139.1, 138.6, 132.5, 129.1, 128.2, 126.1, 125.3, 124.8, 118.9, 110.6, 41.3; IR (KBr) $v\left(\mathrm{~cm}^{-1}\right): 3160\left(\mathrm{~N}-\mathrm{H}_{\text {amide }}\right), 3066\left(\mathrm{C}-\mathrm{H}_{\text {arom }}\right), 1636\left(\mathrm{C}=\mathrm{O}_{\text {ketone }}\right), 1603\left(\mathrm{C}=\mathrm{O}_{\text {amide }}\right)$.

6-Chloro-4-oxo-N'-(4-chlorobenzyl)-1,4-dihydroquinoline-3-carboxamide (10b): yield: $1.2 \mathrm{~g}(85 \%)$ as a light brown solid; m.p.: $262-263{ }^{\circ} \mathrm{C} ;{ }^{1} \mathrm{H}-\mathrm{NMR}\left(500.00 \mathrm{MHz}, \mathrm{DMSO}-d_{6}\right) \delta(\mathrm{ppm}): 10.58(1 \mathrm{H}, \mathrm{t}, J=5.8 \mathrm{~Hz}$, $\mathrm{C}=\mathrm{ONH}), 8.79(1 \mathrm{H}, \mathrm{s}, \mathrm{H}-2), 8.15(1 \mathrm{H}, \mathrm{t}, J=1.5 \mathrm{~Hz}, \mathrm{H}-7), 7.69(1 \mathrm{H}, \mathrm{d}, J=1.8 \mathrm{~Hz}, \mathrm{H}-5), 7.36(5 \mathrm{H}, \mathrm{m}$, H-8, H-2', H-3', H-5' and H-6'), $4.53\left(2 \mathrm{H}, \mathrm{d}, J=2.7 \mathrm{~Hz}, \mathrm{NHCH}_{2}\right) ;{ }^{13} \mathrm{C}-\mathrm{NMR}\left(125.0 \mathrm{MHz}, \mathrm{DMSO}-d_{6}\right) \delta$ (ppm): 174.2, 165.2, 146.3, 140.6, 138.8, 131.6, 131.2, 129.6, 129.1, 128.7, 128.2, 128.1, 127.6, 110.3, 43.3; IR (KBr) $v\left(\mathrm{~cm}^{-1}\right): 3150\left(\mathrm{~N}-\mathrm{H}_{\text {amide }}\right), 3054\left(\mathrm{C}-\mathrm{H}_{\text {arom }}\right), 1631\left(\mathrm{C}=\mathrm{O}_{\text {ketone }}\right), 1605\left(\mathrm{C}=\mathrm{O}_{\text {amide }}\right)$.

7-Chloro-4-oxo-N'-(4-chlorobenzyl)-1,4-dihydroquinoline-3-carboxamide (10c): yield: $1.1 \mathrm{~g}(79 \%)$ as a light brown solid; m.p.: 220-221 ${ }^{\circ} \mathrm{C}$; ${ }^{1} \mathrm{H}-\mathrm{NMR}\left(500.00 \mathrm{MHz}, \mathrm{DMSO}-d_{6}\right) \delta(\mathrm{ppm}): 10.42(1 \mathrm{H}, \mathrm{t}$, $J=5.8 \mathrm{~Hz}, \mathrm{C}=\mathrm{ONH}), 8.89(1 \mathrm{H}, \mathrm{s}, \mathrm{H}-2), 8.34(1 \mathrm{H}, \mathrm{d}, J=8.5 \mathrm{~Hz}, \mathrm{H}-5), 7.85(1 \mathrm{H}, \mathrm{m}, \mathrm{H}-8), 7.59(1 \mathrm{H}, \mathrm{m}$, H-6), 7.48 (4H, d, $J=7.3 \mathrm{~Hz}, \mathrm{H}-2{ }^{\prime}, \mathrm{H}-3{ }^{\prime}, \mathrm{H}-5$ ' and H-6'), $4.71\left(2 \mathrm{H}, \mathrm{d}, J=6.1 \mathrm{~Hz}, \mathrm{NHCH}_{2}\right) ;{ }^{13} \mathrm{C}-\mathrm{NMR}$ (125.0 MHz, DMSO- $\left.d_{6}\right) \delta(\mathrm{ppm}): 175.5,164.3,144.5,139.9,138.5,137.2,131.3,129.1,128.3,127.6$, 125.2, 124.7, 118.2, 111.2, 41.4; IR (KBr) $v\left(\mathrm{~cm}^{-1}\right): 3150\left(\mathrm{~N}-\mathrm{H}_{\text {amide }}\right), 3052\left(\mathrm{C}-\mathrm{H}_{\text {arom }}\right), 1655\left(\mathrm{C}=\mathrm{O}_{\text {ketone }}\right)$, $1627\left(\mathrm{C}=\mathrm{O}_{\text {amide }}\right)$.

4-Oxo-N'-cyclohexyl-1,4-dihydroquinoline-3-carboxamide (11a): yield: $0.4 \mathrm{~g} \mathrm{(30 \% )}$ as a white solid; m.p.: 209-212 ${ }^{\circ} \mathrm{C}$; ${ }^{1} \mathrm{H}-\mathrm{NMR}\left(500.00 \mathrm{MHz}, \mathrm{DMSO}-d_{6}\right) \delta(\mathrm{ppm}): 10.10(1 \mathrm{H}, \mathrm{d}, J=7.7 \mathrm{~Hz}, \mathrm{C}=\mathrm{ON} H)$, $8.75(1 \mathrm{H}, \mathrm{s}, \mathrm{H}-2), 8.30(1 \mathrm{H}, \mathrm{dd}, J=8.2$ and $1.1 \mathrm{~Hz}, \mathrm{H}-5), 7.81-7.77(1 \mathrm{H}, \mathrm{m}, \mathrm{H}-7), 7.72(1 \mathrm{H}, \mathrm{d}, J=8.1$ Hz, H-8), 7.53-7.48 (1H, m, H-6), 3.89 (1H, m, H-1'), 1.89 (2H, m, H-2' axial and H-6 $\left.6_{\text {axial }}\right), 1.72$ (2H, dd, $J=9.3$ and $3.7 \mathrm{~Hz}, \mathrm{H}-3^{\prime}$ axial and $\left.\mathrm{H}^{\prime} 5^{\prime}{ }_{\text {axial }}\right), 1.59\left(1 \mathrm{H}, \mathrm{dd}, J=9.3\right.$ and $\left.3.2 \mathrm{~Hz}, \mathrm{H}-4^{\prime}\right), 1.39(5 \mathrm{H}, \mathrm{m}$,

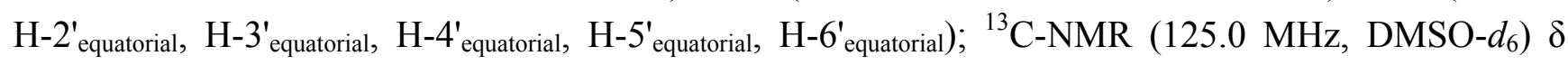
(ppm): 176.1, 163.3, 143.3, 139.0, 132.4, 126.1, 125.3, 124.7, 118.8, 111.0, 46.6, 32.4, 25.2, 24.0; $\operatorname{IR}(\mathrm{KBr}) v\left(\mathrm{~cm}^{-1}\right): 3433\left(\mathrm{~N}-\mathrm{H}_{\text {amide }}\right), 1644\left(\mathrm{C}=\mathrm{O}_{\text {ketone }}\right), 1617\left(\mathrm{C}=\mathrm{O}_{\text {amide }}\right)$.

6-Chloro-4-oxo-N'-cyclohexyl-1,4-dihydroquinoline-3-carboxamide (11b): yield: $1.4 \mathrm{~g}(58 \%)$ as a white solid; m.p.: $140-142{ }^{\circ} \mathrm{C}$; ${ }^{1} \mathrm{H}-\mathrm{NMR}\left(500.00 \mathrm{MHz}, \mathrm{DMSO}-d_{6}\right) \delta(\mathrm{ppm}): 9.91(1 \mathrm{H}, \mathrm{d}, J=7.8 \mathrm{~Hz}$, $\mathrm{C}=\mathrm{ONH}), 8.73(1 \mathrm{H}, \mathrm{s}, \mathrm{H}-2), 8.17(1 \mathrm{H}, \mathrm{d}, J=2.3 \mathrm{~Hz}, \mathrm{H}-5), 7.77(1 \mathrm{H}, \mathrm{dd}, J=8.8$ and $2.3 \mathrm{~Hz}, \mathrm{H}-7)$, $7.72(1 \mathrm{H}, \mathrm{d}, J=8.8 \mathrm{~Hz}, \mathrm{H}-8), 3.84\left(1 \mathrm{H}, \mathrm{m}, \mathrm{H}-1^{\prime}\right), 1.87\left(2 \mathrm{H}, \mathrm{m}, \mathrm{H}-2_{\text {axial }}^{\prime}\right.$ and $\left.\mathrm{H}-6_{\text {axial }}^{\prime}\right), 1.67$ (2H, m,

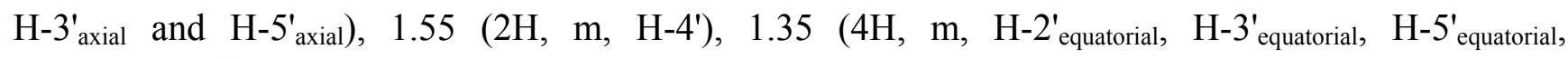

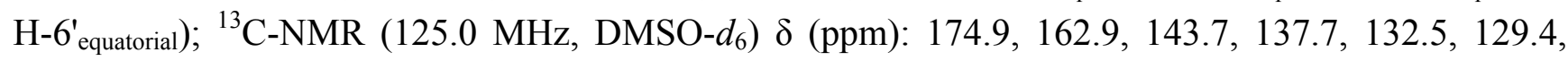
127.1, 124.2, 121.3, 111.3, 46.7, 32.4, 25.1, 24.0; IR (KBr) $v\left(\mathrm{~cm}^{-1}\right): 3459\left(\mathrm{~N}-\mathrm{H}_{\text {amide }}\right), 3063\left(\mathrm{C}-\mathrm{H}_{\text {arom }}\right)$, $1651\left(\mathrm{C}=\mathrm{O}_{\text {ketone }}\right), 1618\left(\mathrm{C}=\mathrm{O}_{\text {amide }}\right)$.

7-Chloro-4-oxo-N'-cyclohexyl-1,4-dihydroquinoline-3-carboxamide (11c): yield: $1.8 \mathrm{~g}(75 \%)$ as a white solid; m.p.: $140-141{ }^{\circ} \mathrm{C}$; ${ }^{1} \mathrm{H}-\mathrm{NMR}\left(500.00 \mathrm{MHz}, \mathrm{DMSO}-d_{6}\right) \delta$ (ppm): $9.97(1 \mathrm{H}, \mathrm{d}, J=7.7 \mathrm{~Hz}$, 
$\mathrm{C}=\mathrm{ONH}), 8.74(1 \mathrm{H}, \mathrm{s}, \mathrm{H}-2), 8.22(1 \mathrm{H}, \mathrm{d}, J=8.7 \mathrm{~Hz}, \mathrm{H}-5), 7.72(1 \mathrm{H}, \mathrm{s}, \mathrm{H}-8), 7.46(1 \mathrm{H}, \mathrm{d}, J=8.7 \mathrm{~Hz}$, $\mathrm{H}-6), 3.83\left(1 \mathrm{H}, \mathrm{m}, \mathrm{H}-1^{\prime}\right), 1.84$ (2H, m, H-2' ${ }_{\text {axial }}$ and $\left.\mathrm{H}-6^{\prime}{ }_{\text {axial }}\right), 1.67$ (2H, m, H-3' ${ }^{\prime}$ axial and $\mathrm{H}-5^{\prime}{ }_{\text {axial }}$ ),

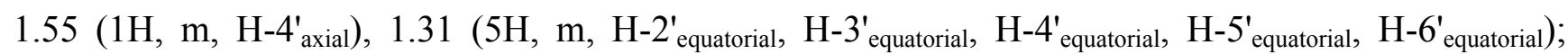
${ }^{13} \mathrm{C}-\mathrm{NMR}\left(125.0 \mathrm{MHz}, \mathrm{DMSO}-d_{6}\right) \delta$ (ppm): 175.5, 163.1, 144.5, 140.2, 137.0, 127.6, 125.0, 124.8, 118.4, 111.5, 46.7, 32.5, 25.2, 24.1; IR $(\mathrm{KBr}) \vee\left(\mathrm{cm}^{-1}\right): 3460\left(\mathrm{~N}-\mathrm{H}_{\text {amide }}\right), 3062\left(\mathrm{C}-\mathrm{H}_{\text {arom }}\right), 1630$ $\left(\mathrm{C}=\mathrm{O}_{\text {ketone }}\right), 1570\left(\mathrm{C}=\mathrm{O}_{\text {amide }}\right)$.

4-oxo-N'-(4-Chlorophenyl)-1,4-dihydroquinoline-3-carboxamide (12a): yield: $1.3 \mathrm{~g}(96 \%)$ as a bright white solid; m.p.: $>300{ }^{\circ} \mathrm{C} ;{ }^{1} \mathrm{H}-\mathrm{NMR}\left(500.00 \mathrm{MHz}, \mathrm{DMSO}-d_{6}\right) \delta(\mathrm{ppm}): 12.54(1 \mathrm{H}, \mathrm{s}, \mathrm{C}=\mathrm{ON} H), 8.86$ $(1 \mathrm{H}, \mathrm{s}, \mathrm{H}-2), 8.32(1 \mathrm{H}, \mathrm{dd}, J=8.3$ and $1.0 \mathrm{~Hz}, \mathrm{H}-5), 7.82-7.79(1 \mathrm{H}, \mathrm{m}, \mathrm{H}-7), 7.76(2 \mathrm{H}, \mathrm{d}, J=8.9 \mathrm{~Hz}$, H-2' and H-6'), $7.74(1 \mathrm{H}, \mathrm{d}, J=8.0 \mathrm{~Hz}, \mathrm{H}-8), 7.53$ (1H, m, H-6), 7.39 (2H, d, $J=8.5 \mathrm{~Hz}, \mathrm{H}-3^{\prime}$ and H-5'); ${ }^{13} \mathrm{C}-\mathrm{NMR}\left(125.0 \mathrm{MHz}, \mathrm{DMSO}-d_{6}\right) \delta$ (ppm): 176.2, 162.8, 144.1, 138.9, 137.5, 132.9, 128.7, 126.7, 125.7, 125.3, 125.2, 121.0, 119.1, 110.2; IR (KBr) $\vee\left(\mathrm{cm}^{-1}\right)$ : $3209(\mathrm{~N}-\mathrm{H}$ amide), 3064 (C-H arom), $1665\left(\mathrm{C}=\mathrm{O}_{\text {ketone }}\right), 1626(\mathrm{C}=\mathrm{O}$ amide $)$.

6-Chloro-4-oxo- $N^{\prime}$-(4-chlorophenyl)-1,4-dihydroquinoline-3-carboxamide (12b): yield: $1.3 \mathrm{~g}(98 \%)$ as a bright purple solid; m.p.: $>300{ }^{\circ} \mathrm{C} ;{ }^{1} \mathrm{H}-\mathrm{NMR}\left(500.00 \mathrm{MHz}, \mathrm{DMSO}-d_{6}\right) \delta(\mathrm{ppm}): 12.32(1 \mathrm{H}, \mathrm{s}$, $\mathrm{C}=\mathrm{ONH}), 8.86(1 \mathrm{H}, \mathrm{s}, \mathrm{H}-2), 8.21(1 \mathrm{H}, \mathrm{d}, J=2.3 \mathrm{~Hz}, \mathrm{H}-5), 7.81(1 \mathrm{H}, \mathrm{dd}, J=8.8$ and $2.4 \mathrm{~Hz}, \mathrm{H}-7)$, $7.76(1 \mathrm{H}, \mathrm{d}, J=8.8 \mathrm{~Hz}, \mathrm{H}-8), 7.73\left(2 \mathrm{H}, \mathrm{d}, J=8.8 \mathrm{~Hz}, \mathrm{H}-2^{\prime}\right.$ and $\left.\mathrm{H}-3^{\prime}\right), 7.39\left(2 \mathrm{H}, \mathrm{d}, J=8.8 \mathrm{~Hz}, \mathrm{H}-3^{\prime}\right.$ and $\left.\mathrm{H}^{\prime}{ }^{\prime}\right) ;{ }^{13} \mathrm{C}-\mathrm{NMR}\left(125.0 \mathrm{MHz}, \mathrm{DMSO}-d_{6}\right) \delta(\mathrm{ppm}): 175.0,162.5,144.4,137.6,137.4,132.9,129.9$, 128.7, 126.9, 126.8, 124.3, 121.5, 121.1, 110.6; IR (KBr) $v\left(\mathrm{~cm}^{-1}\right): 3206\left(\mathrm{~N}_{-} \mathrm{H}_{\text {amide }}\right), 3063\left(\mathrm{C}-\mathrm{H}_{\text {arom }}\right)$, $1663\left(\mathrm{C}=\mathrm{O}_{\text {ketone }}\right), 1595\left(\mathrm{C}=\mathrm{O}_{\text {amide }}\right)$.

4-oxo-N'-(4-Fluorophenyl)-1,4-dihydroquinoline-3-carboxamide (13a): yield: $1.2 \mathrm{~g}(94 \%)$ as a bright purple solid; m.p.: $>300{ }^{\circ} \mathrm{C}$; ${ }^{1} \mathrm{H}-\mathrm{NMR}\left(500.00 \mathrm{MHz}, \mathrm{DMSO}-d_{6}\right) \delta(\mathrm{ppm}): 12.47(1 \mathrm{H}, \mathrm{s}, \mathrm{C}=\mathrm{ONH}), 8.86$ $(1 \mathrm{H}, \mathrm{s}, \mathrm{H}-2), 8.32(1 \mathrm{H}, \mathrm{dd}, J=8.3$ and $1.4 \mathrm{~Hz}, \mathrm{H}-5), 7.80(1 \mathrm{H}, \mathrm{td}, J=8.3$ and $1.4 \mathrm{~Hz}, \mathrm{H}-7), 7.75$ (2H, dd, $J=9.2$ and $4.8 \mathrm{~Hz}, \mathrm{H}-2^{\prime}$ and $\left.\mathrm{H}-6^{\prime}\right), 7.73(1 \mathrm{H}, \mathrm{d}, J=7.8 \mathrm{~Hz}, \mathrm{H}-8), 7.53(1 \mathrm{H}, \mathrm{td}, J=8.3$ and $0.9 \mathrm{~Hz}, \mathrm{H}-6)$ $\left.7.18\left(2 \mathrm{H}, \mathrm{t}, J=8.8 \mathrm{~Hz}, \mathrm{H}-3^{\prime} \text { and } \mathrm{H}_{-5}\right)^{\prime}\right) ;{ }^{13} \mathrm{C}-\mathrm{NMR}\left(125.0 \mathrm{MHz}, \mathrm{DMSO}-d_{6}\right) \delta$ (ppm): 176.2, 162.7, $158.0\left(\mathrm{~d},{ }^{1} J_{\mathrm{C}-\mathrm{F}}=240.0 \mathrm{~Hz}\right), 144.0,139.0,135.1,132.8,125.8,125.2\left(\mathrm{~d},{ }^{3} J_{\mathrm{C}-\mathrm{F}}=7.7 \mathrm{~Hz}\right), 121.2,121.1$, 119.1, $115.4\left(\mathrm{~d},{ }^{2} J_{\mathrm{C}-\mathrm{F}}=22.1 \mathrm{~Hz}\right), 110.3$; IR $(\mathrm{KBr}) \vee\left(\mathrm{cm}^{-1}\right): 3211\left(\mathrm{~N}-\mathrm{H}_{\text {amide }}\right), 3067\left(\mathrm{C}-\mathrm{H}_{\text {arom }}\right)$, $1666\left(\mathrm{C}=\mathrm{O}_{\text {ketone }}\right), 1625\left(\mathrm{C}=\mathrm{O}_{\text {amide }}\right)$.

7-Chloro-4-oxo-N'-(4-fluorphenyl)-1,4-dihydroquinoline-3-carboxamide (13b): yield: $1.01 \mathrm{~g}(80 \%)$ as a bright gray solid; m.p.: $>300{ }^{\circ} \mathrm{C}$; ${ }^{1} \mathrm{H}-\mathrm{NMR}\left(500.00 \mathrm{MHz}, \mathrm{DMSO}-d_{6}\right) \delta(\mathrm{ppm}): 12.28(1 \mathrm{H}, \mathrm{s}$, $\mathrm{C}=\mathrm{ONH}), 8.88(1 \mathrm{H}, \mathrm{s}, \mathrm{H}-2), 8.28(1 \mathrm{H}, \mathrm{d}, J=8.7 \mathrm{~Hz}, \mathrm{H}-5), 7.77(1 \mathrm{H}, \mathrm{d}, J=1.9 \mathrm{~Hz}, \mathrm{H}-8), 7.73(2 \mathrm{H}, \mathrm{dd}$, $J=9.1$ and $4.9 \mathrm{~Hz}, \mathrm{H}-2^{\prime}$ and $\left.\mathrm{H}-6^{\prime}\right), 7.53(1 \mathrm{H}, \mathrm{dd}, J=8.7$ and $1.9 \mathrm{~Hz}, \mathrm{H}-6), 7.18\left(2 \mathrm{H}, \mathrm{d}, J=8.9 \mathrm{~Hz}, \mathrm{H}-3^{\prime}\right.$ and $\left.\mathrm{H}_{-5}{ }^{\prime}\right) ;{ }^{13} \mathrm{C}-\mathrm{NMR}\left(75.0 \mathrm{MHz}\right.$, DMSO- $\left.d_{6}\right) \delta$ (ppm): 175.6, 162.3, 159.6, 156.4, 144.7, 139.8, 137.40, 134.9, 127.5, 125.4, 124.4, 121.3, 121.1, 118.3, 115.5, 115.2, 110.9; IR (KBr) $v\left(\mathrm{~cm}^{-1}\right)$ : $3069\left(\mathrm{C}-\mathrm{H}_{\text {arom }}\right), 1664\left(\mathrm{C}=\mathrm{O}_{\text {ketone }}\right), 1614\left(\mathrm{C}=\mathrm{O}_{\text {amide }}\right)$; HRMS-ESI $(\mathrm{m} / \mathrm{z})$ : found for $\mathrm{C}_{16} \mathrm{H}_{10} \mathrm{ClFN}_{2} \mathrm{O}_{2}$ $[\mathrm{M}+\mathrm{H}]^{+}: 317.0488$.

4-oxo-N'-(4-Methoxyphenyl)-1,4-dihydroquinoline-3-carboxamide (14a): yield: $1.2 \mathrm{~g}(86 \%)$ as a bright blue solid; m.p.: $>300{ }^{\circ} \mathrm{C}$; ${ }^{1} \mathrm{H}-\mathrm{NMR}\left(500.00 \mathrm{MHz}, \mathrm{DMSO}-d_{6}\right) \delta(\mathrm{ppm}): 12.30(1 \mathrm{H}, \mathrm{s}, \mathrm{C}=\mathrm{ON} H), 8.85$ 
$(1 \mathrm{H}, \mathrm{s}, \mathrm{H}-2), 8.32(1 \mathrm{H}, \mathrm{dd}, J=8.1$ and $1.1 \mathrm{~Hz}, \mathrm{H}-5), 7.79(1 \mathrm{H}, \mathrm{td}, J=8.3$ and $1.4 \mathrm{~Hz}, \mathrm{H}-7), 7.73(1 \mathrm{H}$, d, $J=8.1 \mathrm{~Hz}, \mathrm{H}-8), 7.64\left(2 \mathrm{H}, \mathrm{d}, J=9.0 \mathrm{~Hz}, \mathrm{H}-33^{\prime}\right.$ and H-5'), $7.52(1 \mathrm{H}, \mathrm{t}, J=7.8 \mathrm{~Hz}, \mathrm{H}-6), 6.93(2 \mathrm{H}, \mathrm{d}$, $J=9.0 \mathrm{~Hz}, \mathrm{H}-2^{\prime}$ and H-6'), $3.75\left(3 \mathrm{H}, \mathrm{s}, \mathrm{OCH}_{3}\right) ;{ }^{13} \mathrm{C}-\mathrm{NMR}\left(125.0 \mathrm{MHz}, \mathrm{DMSO}-d_{6}\right) \delta(\mathrm{ppm}): 176.2$, $162.3,155.2,143.8,139.0,132.8,131.9,125.8,125.3,125.0,120.9,119.0,114.0,110.6,55.1$; $\operatorname{IR}(\mathrm{KBr}) v\left(\mathrm{~cm}^{-1}\right): 3212\left(\mathrm{~N}-\mathrm{H}_{\text {amide }}\right), 3064\left(\mathrm{C}-\mathrm{H}_{\text {arom }}\right), 1659\left(\mathrm{C}=\mathrm{O}_{\text {ketone }}\right), 1606\left(\mathrm{C}=\mathrm{O}_{\text {amide }}\right)$.

7-Chloro-4-oxo-N'-(4-methoxyphenyl)-1,4-dihydroquinoline-3-carboxamide (14b): yield: $1.14 \mathrm{~g}$ (87\%) as a bright purple solid; m.p.: $270-273{ }^{\circ} \mathrm{C} ;{ }^{1} \mathrm{H}-\mathrm{NMR}\left(500.00 \mathrm{MHz}, \mathrm{DMSO}-d_{6}\right) \delta(\mathrm{ppm}): 12.12(1 \mathrm{H}, \mathrm{s}$, $\mathrm{C}=\mathrm{ONH}), 8.87(1 \mathrm{H}, \mathrm{s}, \mathrm{H}-2), 8.29(1 \mathrm{H}, \mathrm{d}, J=8.7 \mathrm{~Hz}, \mathrm{H}-5), 7.78(1 \mathrm{H}, \mathrm{d}, J=1.9 \mathrm{~Hz}, \mathrm{H}-8), 7.63(2 \mathrm{H}, \mathrm{d}$, $J=9.0 \mathrm{~Hz}, \mathrm{H}-3^{\prime}$ and $\left.\mathrm{H}^{\prime} 5^{\prime}\right), 7.53(1 \mathrm{H}, \mathrm{dd}, J=8.7$ and $1.9 \mathrm{~Hz}, \mathrm{H}-6), 6.93\left(2 \mathrm{H}, \mathrm{d}, J=9.0 \mathrm{~Hz}, \mathrm{H}-2^{\prime}\right.$ and H-6'), $3.87\left(3 \mathrm{H}, \mathrm{s}, \mathrm{OCH}_{3}\right) ;{ }^{13} \mathrm{C}-\mathrm{NMR}\left(75.0 \mathrm{MHz}, \mathrm{DMSO}-d_{6}\right) \delta(\mathrm{ppm}): 175.6,161.9,155.2,146.5,139.8$, $137.3,131.7,127.5,125.3,124.4,120.9,118.2,114.0,111.2,55.0 ; \quad$ IR $(\mathrm{KBr}) \quad v\left(\mathrm{~cm}^{-1}\right)$ : $3201\left(\mathrm{~N}-\mathrm{H}_{\text {amide }}\right), 3070\left(\mathrm{C}-\mathrm{H}_{\text {arom }}\right), 1657\left(\mathrm{C}=\mathrm{O}_{\text {ketone }}\right), 1621\left(\mathrm{C}=\mathrm{O}_{\text {amide }}\right)$; HRMS-ESI $(\mathrm{m} / \mathrm{z})$ : found for $\mathrm{C}_{17} \mathrm{H}_{13} \mathrm{ClN}_{2} \mathrm{O}_{3}[\mathrm{M}+\mathrm{H}]^{+}: 329.0687$.

4-oxo- $N$ '-Phenyl-1,4-dihydroquinoline-3-carboxamide (15a): yield: $0.9 \mathrm{~g} \mathrm{(79 \% )} \mathrm{as} \mathrm{a} \mathrm{light} \mathrm{brown} \mathrm{solid;}$ m.p.: $>300{ }^{\circ} \mathrm{C} ;{ }^{1} \mathrm{H}-\mathrm{NMR}\left(500.00 \mathrm{MHz}, \mathrm{DMSO}_{-} d_{6}\right)(\mathrm{ppm}): 12.48(1 \mathrm{H}, \mathrm{s}, \mathrm{C}=\mathrm{ONH}), 8.90(1 \mathrm{H}, \mathrm{s}, \mathrm{H}-2)$, $8.38(1 \mathrm{H}, \mathrm{dd}, J=8.1$ and $0.9 \mathrm{~Hz}, \mathrm{H}-5), 7.87-782(1 \mathrm{H}, \mathrm{m}, \mathrm{H}-7), 7.78\left(1 \mathrm{H}, \mathrm{m}, \mathrm{H}-8, \mathrm{H}-2^{\prime}\right.$ and H-6'), $7.57(1 \mathrm{H}, \mathrm{m}, \mathrm{H}-6), 7.40\left(2 \mathrm{H}, \mathrm{t}, J=7.9 \mathrm{~Hz}, \mathrm{H}-3^{\prime}\right.$ and $\left.\mathrm{H}-5^{\prime}\right), 7.13\left(1 \mathrm{H}, \mathrm{t}, J=7.4 \mathrm{~Hz}, \mathrm{H}-4^{\prime}\right)$; ${ }^{13} \mathrm{C}-\mathrm{NMR}$ (125.0 MHz, DMSO- $\left.d_{6}\right) \delta(\mathrm{ppm}): 176.2,162.7,143.9,139.0,138.7,132.8,128.8,125.9,125.4,125.1$, 123.3, 119.5, 119.0, 110.6; IR $(\mathrm{KBr}) \vee\left(\mathrm{cm}^{-1}\right): 3255\left(\mathrm{~N}-\mathrm{H}_{\text {amide }}\right), 3065\left(\mathrm{C}-\mathrm{H}_{\text {arom }}\right), 1667\left(\mathrm{C}=\mathrm{O}_{\text {ketone }}\right)$, $1618\left(\mathrm{C}=\mathrm{O}_{\text {amide }}\right)$.

6-Chloro-4-oxo-N'-phenyl-1,4-dihydroquinoline-3-carboxamide (15b): yield: $1.0 \mathrm{~g}(85 \%)$ as a bright white solid; m.p.: $>300{ }^{\circ} \mathrm{C} ;{ }^{1} \mathrm{H}-\mathrm{NMR}\left(500.00 \mathrm{MHz}\right.$, DMSO- $\left.d_{6}\right) \delta(\mathrm{ppm}): 12.27(1 \mathrm{H}, \mathrm{s}, \mathrm{C}=\mathrm{ONH}), 8.88$ $(1 \mathrm{H}, \mathrm{s}, \mathrm{H}-2), 8.23(1 \mathrm{H}, \mathrm{d}, J=2.4 \mathrm{~Hz}, \mathrm{H}-5), 7.83(1 \mathrm{H}, \mathrm{dd}, J=8.8$ and $2.4 \mathrm{~Hz}, \mathrm{H}-7), 7.77(1 \mathrm{H}, \mathrm{d}, J=8.8$ Hz, H-8), 7.71 (2H, d, $J=8.4 \mathrm{~Hz}, \mathrm{H}-2^{\prime}$ and H-6'), 7.36 (2H, t, $J=7.9 \mathrm{~Hz}, \mathrm{H}-3^{\prime}$ and H-5'), 7.12-7.07 $\left(1 \mathrm{H}, \mathrm{m}, \mathrm{H}-4^{\prime}\right) ;{ }^{13} \mathrm{C}-\mathrm{NMR}\left(125.0 \mathrm{MHz}, \mathrm{DMSO}-d_{6}\right) \delta(\mathrm{ppm}): 175.1,162.4,144.5,138.6,137.8,132.9$, 128.9, 128.9, 127.0, 124.4, 123.4, 121.6, 119.6, 110.9; IR (KBr) $v\left(\mathrm{~cm}^{-1}\right): 3204\left(\mathrm{~N}-\mathrm{H}_{\text {amide }}\right), 3058$ (C$\left.\mathrm{H}_{\text {arom }}\right), 1653\left(\mathrm{C}=\mathrm{O}_{\text {ketone }}\right), 1597\left(\mathrm{C}=\mathrm{O}_{\text {amide }}\right)$.

7-Chloro-4-oxo-N'-phenyl-1,4-dihydroquinoline-3-carboxamide (15c): yield: $1.0 \mathrm{~g}(83 \%)$ as a light brown solid; m.p.: $>300{ }^{\circ} \mathrm{C}$; ${ }^{1} \mathrm{H}-\mathrm{NMR}\left(500.00 \mathrm{MHz}, \mathrm{DMSO}-d_{6}\right) \delta(\mathrm{ppm}): 12.28(1 \mathrm{H}, \mathrm{s}, \mathrm{C}=\mathrm{ONH}), 8.89$ $(1 \mathrm{H}, \mathrm{s}, \mathrm{H}-2), 8.29(1 \mathrm{H}, \mathrm{d}, J=8.7 \mathrm{~Hz}, \mathrm{H}-5), 7.77(1 \mathrm{H}, \mathrm{d}, J=1.8 \mathrm{~Hz}, \mathrm{H}-8), 7.71\left(1 \mathrm{H}, \mathrm{d}, J=7.6 \mathrm{~Hz}, \mathrm{H}-2^{\prime}\right.$ and H-6'), $7.53(1 \mathrm{H}, \mathrm{dd}, J=8.7$ and $1.9 \mathrm{~Hz}, \mathrm{H}-6), 7.36\left(2 \mathrm{H}, \mathrm{t}, J=7.9 \mathrm{~Hz}, \mathrm{H}-3^{\prime}\right.$ and H-5'), 7.09 (1H, t, $\left.J=7.4 \mathrm{~Hz}, \mathrm{H}-4^{\prime}\right) ;{ }^{13} \mathrm{C}-\mathrm{NMR}\left(125.0 \mathrm{MHz}, \mathrm{DMSO}-d_{6}\right) \delta(\mathrm{ppm}): 175.7,162.4,144.8,139.8,138.6$, 137.5, 128.9, 127.7, 125.5, 124.6, 123.4, 119.6, 118.3, 111.2; IR (KBr) $v\left(\mathrm{~cm}^{-1}\right): 3204\left(\mathrm{~N}-\mathrm{H}_{\text {amide }}\right), 3069$ $\left(\mathrm{C}-\mathrm{H}_{\text {arom }}\right), 1662\left(\mathrm{C}=\mathrm{O}_{\text {ketone }}\right), 1618\left(\mathrm{C}=\mathrm{O}_{\text {amide }}\right)$.

4-Oxo-N'-(p-tolyl)-1,4-dihydroquinoline-3-carboxamide (16a): yield: $1.2 \mathrm{~g}(94 \%)$ as a bright rose solid; m.p.: $>300{ }^{\circ} \mathrm{C} ;{ }^{1} \mathrm{H}-\mathrm{NMR}\left(500.00 \mathrm{MHz}, \mathrm{DMSO}-d_{6}\right) \delta(\mathrm{ppm}): 12.36(1 \mathrm{H}, \mathrm{s}, \mathrm{C}=\mathrm{ONH}), 8.84(1 \mathrm{H}, \mathrm{s}$, H-2), 8.32 (1H, d, $J=8.2 \mathrm{~Hz}, \mathrm{H}-5), 7.80(1 \mathrm{H}, \mathrm{t}, J=8.3 \mathrm{~Hz}, \mathrm{H}-7), 7.73$ (1H, d, $J=8.2 \mathrm{~Hz}, \mathrm{H}-8), 7.60$ $\left(2 \mathrm{H}, \mathrm{d}, J=8.3 \mathrm{~Hz}, \mathrm{H}-3^{\prime}\right.$ and H-5'), $7.52(1 \mathrm{H}, \mathrm{t}, J=7.9 \mathrm{~Hz}, \mathrm{H}-6), 7.16\left(2 \mathrm{H}, \mathrm{d}, J=8.3 \mathrm{~Hz}, \mathrm{H}-2^{\prime}\right.$ and $\mathrm{H}-$ 
$\left.6^{\prime}\right), 2.27\left(3 \mathrm{H}, \mathrm{s}, \mathrm{CH}_{3}\right) ;{ }^{13} \mathrm{C}-\mathrm{NMR}\left(125.0 \mathrm{MHz}, \mathrm{DMSO}-d_{6}\right) \delta(\mathrm{ppm}): 176.2,162.5,143.9,139.0,136.2$, 132.8, 132.7, 129.3, 125.8, 125.3, 125.1, 119.5, 119.1, 110.6, 20.3; IR (KBr) v (cm $\left.{ }^{-1}\right): 3209\left(\mathrm{~N}-\mathrm{H}_{\text {amide }}\right)$, $3070\left(\mathrm{C}-\mathrm{H}_{\text {arom }}\right), 1663\left(\mathrm{C}=\mathrm{O}_{\text {ketone }}\right), 1604\left(\mathrm{C}=\mathrm{O}_{\text {amide }}\right)$.

6-Chloro-4-oxo-N'-(p-tolyl)-1,4-dihydroquinoline-3-carboxamide (16b): yield: $1.19 \mathrm{~g}(96 \%)$ as a bright gray solid; m.p.: $>300{ }^{\circ} \mathrm{C} ;{ }^{1} \mathrm{H}-\mathrm{NMR}\left(500.00 \mathrm{MHz}, \mathrm{DMSO}-d_{6}\right) \delta(\mathrm{ppm}): 12.18(1 \mathrm{H}, \mathrm{s}, \mathrm{C}=\mathrm{ONH})$, $8.87(1 \mathrm{H}, \mathrm{s}, \mathrm{H}-2), 8.22(1 \mathrm{H}, \mathrm{dd}, J=2.3$ and $0.7 \mathrm{~Hz}, \mathrm{H}-5), 7.82(1 \mathrm{H}, \mathrm{dd}, J=8.9$ and $2.3 \mathrm{~Hz}, \mathrm{H}-7), 7.76$ $(1 \mathrm{H}, \mathrm{dd}, J=8.9$ and $0.7 \mathrm{~Hz}, \mathrm{H}-8), 7.58\left(2 \mathrm{H}, \mathrm{d}, J=8.6 \mathrm{~Hz}, \mathrm{H}-3^{\prime}\right.$ and $\left.\mathrm{H}-5^{\prime}\right), 7.16\left(2 \mathrm{H}, \mathrm{d}, J=8.6 \mathrm{~Hz}, \mathrm{H}-2^{\prime}\right.$ and $\left.\mathrm{H}_{-} 6^{\prime}\right), 2.27\left(3 \mathrm{H}, \mathrm{s}, \mathrm{CH}_{3}\right) ;{ }^{13} \mathrm{C}-\mathrm{NMR}\left(75.0 \mathrm{MHz}, \mathrm{DMSO}-d_{6}\right) \delta(\mathrm{ppm}): 174.9,162.1,144.1,137.7$, 136.0, 132.8, 132.3, 129.7, 129.2, 126.9, 124.2, 121.5, 119.4, 110.9, 20.3; IR $(\mathrm{KBr}) v\left(\mathrm{~cm}^{-1}\right)$ : $3155\left(\mathrm{~N}-\mathrm{H}_{\text {amide }}\right), 3065\left(\mathrm{C}-\mathrm{H}_{\text {arom }}\right), 1662\left(\mathrm{C}=\mathrm{O}_{\text {ketone }}\right), 1605\left(\mathrm{C}=\mathrm{O}_{\text {amide }}\right)$; HRMS-ESI $(\mathrm{m} / \mathrm{z})$ : found for $\mathrm{C}_{17} \mathrm{H}_{13} \mathrm{ClN}_{2} \mathrm{O}_{2}[\mathrm{M}+\mathrm{H}]^{+}: 313.0738$; HPLC chromatogram (see Supporting Information).

7-Chloro-4-oxo-N'-(p-tolyl)-1,4-dihydroquinoline-3-carboxamide (16c): yield: $1.07 \mathrm{~g}(86 \%)$ as a green solid; m.p.: $>300{ }^{\circ} \mathrm{C} ;{ }^{1} \mathrm{H}-\mathrm{NMR}\left(500.00 \mathrm{MHz}, \mathrm{DMSO}-d_{6}\right) \delta(\mathrm{ppm}): 12.18(1 \mathrm{H}, \mathrm{s}, \mathrm{C}=\mathrm{ONH}), 8.87(1 \mathrm{H}, \mathrm{s}$, $\mathrm{H}-2), 8.28(1 \mathrm{H}, \mathrm{d}, J=8.8 \mathrm{~Hz}, \mathrm{H}-5), 7.76(1 \mathrm{H}, \mathrm{d}, J=1.8 \mathrm{~Hz}, \mathrm{H}-8), 7.59\left(2 \mathrm{H}, \mathrm{d}, J=8.2 \mathrm{~Hz}, \mathrm{H}-3{ }^{\prime}\right.$ and H5'), $7.52(1 \mathrm{H}, \mathrm{dd}, J=8.8$ and $1.8 \mathrm{~Hz}, \mathrm{H}-6), 7.15\left(2 \mathrm{H}, \mathrm{d}, J=8.2 \mathrm{~Hz}, \mathrm{H}-2^{\prime}\right.$ and $\left.\mathrm{H}-66^{\prime}\right), 2.27\left(3 \mathrm{H}, \mathrm{s}, \mathrm{CH}_{3}\right)$; ${ }^{13} \mathrm{C}-\mathrm{NMR}\left(75.0 \mathrm{MHz}, \mathrm{DMSO}-d_{6}\right) \delta(\mathrm{ppm}): 175.5,162.0,139.7,137.3,135.9,132.2,129.1,127.5$, 125.3, 124.4, 119.4, 118.1, 111.1, 20.2; IR (KBr) $\vee\left(\mathrm{cm}^{-1}\right): 3205\left(\mathrm{~N}-\mathrm{H}_{\text {amide }}\right), 3069\left(\mathrm{C}-\mathrm{H}_{\text {arom }}\right)$, $1681\left(\mathrm{C}=\mathrm{O}_{\text {ketone }}\right), 1602\left(\mathrm{C}=\mathrm{O}_{\text {amide }}\right)$; HRMS-ESI $(\mathrm{m} / \mathrm{z})$ : found for $\mathrm{C}_{17} \mathrm{H}_{13} \mathrm{ClN}_{2} \mathrm{O}_{2}[\mathrm{M}+\mathrm{H}]^{+}: 313.0738$.

4-Oxo- $N^{\prime}-(2,5$-dichlorophenyl)-1,4-dihydroquinoline-3-carboxamide (17a): yield: $1.01 \mathrm{~g}(66 \%)$ as a light brown solid; m.p.: $>300{ }^{\circ} \mathrm{C} ;{ }^{1} \mathrm{H}-\mathrm{NMR}\left(500.00 \mathrm{MHz}, \mathrm{DMSO}-d_{6}\right) \delta(\mathrm{ppm}): 12.98(1 \mathrm{H}, \mathrm{s}, \mathrm{C}=\mathrm{ONH})$, $8.86(1 \mathrm{H}, \mathrm{s}, \mathrm{H}-2), 8.70\left(1 \mathrm{H}, \mathrm{d}, J=2.6 \mathrm{~Hz}, \mathrm{H}-6{ }^{\prime}\right), 8.32(1 \mathrm{H}, \mathrm{dd}, J=8.2$ and $1.0 \mathrm{~Hz}, \mathrm{H}-5), 7.80(1 \mathrm{H}, \mathrm{td}$, $J=8.3$ and $1.3 \mathrm{~Hz}, \mathrm{H}-7), 7.72(1 \mathrm{H}, \mathrm{d}, J=8.2 \mathrm{~Hz}, \mathrm{H}-8), 7.56-7.50\left(2 \mathrm{H}, \mathrm{m}, \mathrm{H}-3{ }^{\prime}\right.$ and H-6), 7.15 (1H, dd, $J=8.6$ and $2.6 \mathrm{~Hz}, \mathrm{H}-4)$ ); ${ }^{13} \mathrm{C}-\mathrm{NMR}\left(75.0 \mathrm{MHz}, \mathrm{DMSO}-d_{6}\right) \delta(\mathrm{ppm}): 176.1,163.5,144.5,138.9$, 136.99, 133.0, 131.7, 130.4, 125.8, 125.4, 125.3, 123.6, 120.7, 120.6, 119.1, 109.8; IR (KBr) v (cm $\left.{ }^{-1}\right)$ : $3264\left(\mathrm{~N}-\mathrm{H}_{\text {amide }}\right), 3023\left(\mathrm{C}-\mathrm{H}_{\text {arom }}\right), 1677\left(\mathrm{C}=\mathrm{O}_{\text {ketone }}\right), 1634\left(\mathrm{C}=\mathrm{O}_{\text {amide }}\right)$; HRMS-ESI $(\mathrm{m} / \mathrm{z})$ : found for $\mathrm{C}_{16} \mathrm{H}_{10} \mathrm{Cl}_{2} \mathrm{~N}_{2} \mathrm{O}_{2}[\mathrm{M}+\mathrm{H}]^{+}: 333.0192$.

6-Chloro-4-oxo-N'-(2,5-dichlorophenyl)-1,4-dihydroquinoline-3-carboxamide (17b): yield: $1.43 \mathrm{~g}$ (98\%) as a bright beige solid; m.p.: $>300{ }^{\circ} \mathrm{C} ;{ }^{1} \mathrm{H}-\mathrm{NMR}\left(500.00 \mathrm{MHz}, \mathrm{DMSO}-d_{6}\right) \delta(\mathrm{ppm}): 12.74(1 \mathrm{H}$, s, C=ONH), $8.85(1 \mathrm{H}, \mathrm{s}, \mathrm{H}-2), 8.65\left(1 \mathrm{H}, \mathrm{d}, J=2.9 \mathrm{~Hz}, \mathrm{H}-6{ }^{\prime}\right), 8.20(1 \mathrm{H}, \mathrm{d}, J=1.9 \mathrm{~Hz}, \mathrm{H}-5), 7.79(1 \mathrm{H}$, $\mathrm{dd}, J=8.8$ and $1.9 \mathrm{~Hz}, \mathrm{H}-7), 7.73(1 \mathrm{H}, \mathrm{d}, J=8.8 \mathrm{~Hz}, \mathrm{H}-8), 7.52\left(1 \mathrm{H}, \mathrm{d}, J=8.8 \mathrm{~Hz}, \mathrm{H}-3{ }^{\prime}\right), 7.14(1 \mathrm{H}$, $\mathrm{dd}, J=8.8$ and $\left.2.9 \mathrm{~Hz}, \mathrm{H}-4{ }^{\prime}\right) ;{ }^{13} \mathrm{C}-\mathrm{NMR}\left(75.0 \mathrm{MHz}, \mathrm{DMSO}-d_{6}\right) \delta(\mathrm{ppm}): 175.0,163.1,144.8,137.6$, 136.8, 133.0, 131.8, 130.4, 130.0, 126.8, 124.4, 123.7, 121.5, 120.6, 110.2; IR (KBr) $v\left(\mathrm{~cm}^{-1}\right): 3213$ $\left(\mathrm{N}-\mathrm{H}_{\text {amide }}\right), 3089\left(\mathrm{C}-\mathrm{H}_{\text {arom }}\right), 1659\left(\mathrm{C}=\mathrm{O}_{\text {ketone }}\right), 1619\left(\mathrm{C}=\mathrm{O}_{\text {amide }}\right) ;$ HRMS-ESI $(\mathrm{m} / \mathrm{z})$ : found for $\mathrm{C}_{16} \mathrm{H}_{9} \mathrm{Cl}_{3} \mathrm{~N}_{2} \mathrm{O}_{2}[\mathrm{M}+\mathrm{H}]^{+}: 366.8970$; HPLC chromatogram (Supporting Information).

7-Chloro-4-oxo-N'-(2,5-dichlorophenyl)-1,4-dihydroquinoline-3-carboxamide (17c): yield: $0.92 \mathrm{~g}$ $(63 \%)$ as a bright beige solid; m.p.: $>300{ }^{\circ} \mathrm{C} ;{ }^{1} \mathrm{H}-\mathrm{NMR}\left(500.00 \mathrm{MHz}, \mathrm{DMSO}-d_{6}\right) \delta(\mathrm{ppm}): 12.33(1 \mathrm{H}$, $\mathrm{s}, \mathrm{C}=\mathrm{ONH}), 8.86(1 \mathrm{H}, \mathrm{s}, \mathrm{H}-2), 8.67\left(1 \mathrm{H}, \mathrm{d}, J=2.6 \mathrm{~Hz}, \mathrm{H}-6^{\prime}\right), 8.28\left(1 \mathrm{H}, \mathrm{d}, J=9.2 \mathrm{~Hz}, \mathrm{H}-3^{\prime}\right), 7.75(1 \mathrm{H}$, $\mathrm{d}, J=1.9 \mathrm{~Hz}, \mathrm{H}-8), 7.54(1 \mathrm{H}, \mathrm{d}, J=8.6 \mathrm{~Hz}, \mathrm{H}-5), 7.50(1 \mathrm{H}, \mathrm{dd}, J=8.6$ and $1.9 \mathrm{~Hz}, \mathrm{H}-6), 7.15(1 \mathrm{H}$, dd, 
$J=8.6$ and $\left.2.6 \mathrm{~Hz}, \mathrm{H}-4^{\prime}\right) ;{ }^{13} \mathrm{C}-\mathrm{NMR}\left(75.0 \mathrm{MHz}, \mathrm{DMSO}-d_{6}\right) \delta(\mathrm{ppm}): 175.5,163.0,145.2,139.7,137.4$, 136.8, 131.7, 130.3, 127.5, 125.4, 124.4, 123.5, 120.7, 120.6, 118.3, 110.4; IR (KBr) v (cm $\left.{ }^{-1}\right): 3204$ $\left(\mathrm{N}-\mathrm{H}_{\text {amide }}\right), 3065\left(\mathrm{C}-\mathrm{H}_{\text {arom }}\right), 1680\left(\mathrm{C}=\mathrm{O}_{\text {ketone }}\right), 1652\left(\mathrm{C}=\mathrm{O}_{\text {amide }}\right)$; HRMS-ESI $(\mathrm{m} / \mathrm{z})$ : found for $\mathrm{C}_{16} \mathrm{H}_{9} \mathrm{Cl}_{3} \mathrm{~N}_{2} \mathrm{O}_{2}$ $[\mathrm{M}+\mathrm{H}]^{+}: 366.9850$.

4-Oxo-N'-(2,5-dimethoxyphenyl)-1,4-dihydroquinoline-3-carboxamide (18a): yield: $0.85 \mathrm{~g}(57 \%)$ as a gray solid; m.p.: $250-251{ }^{\circ} \mathrm{C} ;{ }^{1} \mathrm{H}-\mathrm{NMR}\left(500.00 \mathrm{MHz}, \mathrm{DMSO}-d_{6}\right) \delta(\mathrm{ppm}): 12.50(1 \mathrm{H}, \mathrm{s}, \mathrm{C}=\mathrm{ONH})$, $8.89(1 \mathrm{H}, \mathrm{s}, \mathrm{H}-2), 8.32(1 \mathrm{H}, \mathrm{dd}, J=8.0$ and $1.0 \mathrm{~Hz}, \mathrm{H}-5), 8.21\left(1 \mathrm{H}, \mathrm{d}, J=3.3 \mathrm{~Hz}, \mathrm{H}-6{ }^{\prime}\right), 7.80(1 \mathrm{H}, \mathrm{td}$, $J=8.3$ and $1.3 \mathrm{~Hz}, \mathrm{H}-7), 7.71(1 \mathrm{H}, \mathrm{d}, J=7.6 \mathrm{~Hz}, \mathrm{H}-8), 7.50(1 \mathrm{H}, \mathrm{td}, J=8.3$ and $1.3 \mathrm{~Hz}, \mathrm{H}-6), 6.97$ $\left(1 \mathrm{H}, \mathrm{d}, J=8.9 \mathrm{~Hz}, \mathrm{H}-3^{\prime}\right), 6.59\left(1 \mathrm{H}, \mathrm{dd}, J=8.6\right.$ and $\left.3.0 \mathrm{~Hz}, \mathrm{H}-4^{\prime}\right), 3.87\left(3 \mathrm{H}, \mathrm{s}, \mathrm{OCH}_{3}\right), 3.71(3 \mathrm{H}, \mathrm{s}$, $\left.\mathrm{OCH}_{3}\right) ;{ }^{13} \mathrm{C}-\mathrm{NMR}\left(75.0 \mathrm{MHz}, \mathrm{DMSO}-d_{6}\right) \delta(\mathrm{ppm}): 175.9,162.8,153.0,143.9,142.7,138.9,132.7$, 129.1, 126.0, 125.4, 125.0, 118.9, 111.6, 110.8, 107.0, 106.8; IR (KBr) v $\left(\mathrm{cm}^{-1}\right): 3213\left(\mathrm{~N}-\mathrm{H}_{\text {amide }}\right), 3058$ $\left(\mathrm{C}-\mathrm{H}_{\text {arom }}\right), 1666\left(\mathrm{C}=\mathrm{O}_{\text {ketone }}\right), 1633\left(\mathrm{C}=\mathrm{O}_{\text {amide }}\right)$; HRMS-ESI $(m / z)$ : found for $\mathrm{C}_{18} \mathrm{H}_{16} \mathrm{~N}_{2} \mathrm{O}_{4}[\mathrm{M}+\mathrm{H}]^{+}: 325.1183$.

6-Chloro-4-oxo-N'-(2,5-dimethoxyphenyl)-1,4-dihydroquinoline-3-carboxamide (18b): yield: $0.62 \mathrm{~g}$ (44\%) as a bright gray solid; m.p.: $256-258{ }^{\circ} \mathrm{C}$; ${ }^{1} \mathrm{H}-\mathrm{NMR}\left(500.00 \mathrm{MHz}, \mathrm{DMSO}-d_{6}\right) \delta$ (ppm): 12.41 $(1 \mathrm{H}, \mathrm{s}, \mathrm{C}=\mathrm{ONH}), 8.87(1 \mathrm{H}, \mathrm{s}, \mathrm{H}-2), 8.21\left(1 \mathrm{H}, \mathrm{d}, J=2.9 \mathrm{~Hz}, \mathrm{H}-6{ }^{\prime}\right), 8.26(1 \mathrm{H}, \mathrm{d}, J=1.9 \mathrm{~Hz}, \mathrm{H}-5), 7.81$ $(1 \mathrm{H}, \mathrm{dd}, J=8.9$ and $2.3 \mathrm{~Hz}, \mathrm{H}-7), 7.75(1 \mathrm{H}, \mathrm{d}, J=8.9 \mathrm{~Hz}, \mathrm{H}-8), 6.98\left(1 \mathrm{H}, \mathrm{d}, J=8.9 \mathrm{~Hz}, \mathrm{H}-3{ }^{\prime}\right), 6.60$ $(1 \mathrm{H}, \mathrm{dd}, J=8.9$ and $2.9 \mathrm{~Hz}, \mathrm{H}-4), 3.87\left(3 \mathrm{H}, \mathrm{s}, \mathrm{OCH}_{3}\right), 3.71\left(3 \mathrm{H}, \mathrm{s}, \mathrm{OCH}_{3}\right) ;{ }^{13} \mathrm{C}-\mathrm{NMR}(75.0 \mathrm{MHz}, \mathrm{DMSO}-$ $\left.d_{6}\right) \delta(\mathrm{ppm}): 174.7,162.6,153.0,144.9,142.6,138.2,132.6,129.6,129.0,127.1,124.4,121.8,111.5$, 111.0, 107.0, 106.8, 56.4, 55.2; IR ( KBr) $v\left(\mathrm{~cm}^{-1}\right): 3154\left(\mathrm{~N}-\mathrm{H}_{\text {amide }}\right), 3090\left(\mathrm{C}-\mathrm{H}_{\text {arom }}\right), 1721\left(\mathrm{C}=\mathrm{O}_{\text {ketone }}\right)$, $1695\left(\mathrm{C}=\mathrm{O}_{\text {amide }}\right)$; HRMS-ESI $(\mathrm{m} / \mathrm{z})$ : found for $\mathrm{C}_{18} \mathrm{H}_{15} \mathrm{ClN}_{2} \mathrm{O}_{4}[\mathrm{M}+\mathrm{H}]^{+}: 359.0793$.

7-Chloro-4-oxo-N'-(2,5-dimethoxyphenyl)-1,4-dihydroquinoline-3-carboxamide (18c): yield: $0.64 \mathrm{~g}$ (45\%) as a gray solid; m.p.: $261-262{ }^{\circ} \mathrm{C} ;{ }^{1} \mathrm{H}-\mathrm{NMR}\left(500.00 \mathrm{MHz}, \mathrm{DMSO}-d_{6}\right) \delta(\mathrm{ppm}): 12.38(1 \mathrm{H}, \mathrm{s}$, $\mathrm{C}=\mathrm{ONH}), 8.87(1 \mathrm{H}, \mathrm{s}, \mathrm{H}-2), 8.31(1 \mathrm{H}, \mathrm{d}, J=8.6 \mathrm{~Hz}, \mathrm{H}-5), 8.19(1 \mathrm{H}, \mathrm{d}, J=3.3 \mathrm{~Hz}, \mathrm{H}-6 '), 7.75(1 \mathrm{H}, \mathrm{d}$, $J=1.9 \mathrm{~Hz}, \mathrm{H}-8), 7.51(1 \mathrm{H}, \mathrm{dd}, J=8.6$ and $1.9 \mathrm{~Hz}, \mathrm{H}-6), 6.98(1 \mathrm{H}, \mathrm{d}, J=8.9 \mathrm{~Hz}, \mathrm{H}-3$ '), $6.59(1 \mathrm{H}, \mathrm{dd}$, $J=8.9$ and $2.9 \mathrm{~Hz}, \mathrm{H}-4), 3.87\left(3 \mathrm{H}, \mathrm{s}, \mathrm{OCH}_{3}\right), 3.71\left(3 \mathrm{H}, \mathrm{s}, \mathrm{OCH}_{3}\right) ;{ }^{13} \mathrm{C}-\mathrm{NMR}\left(75.0 \mathrm{MHz}, \mathrm{DMSO}-d_{6}\right) \delta$ (ppm): 175.4, 162.5, 153.0, 144.9, 142.7, 139.9, 137.2, 128.9, 127.7, 125.3, 124.7, 118.3, 111.6, 111.4, 107.0, 106.8, 56.4, 55.2; IR $(\mathrm{KBr}) \vee\left(\mathrm{cm}^{-1}\right): 3401\left(\mathrm{~N}-\mathrm{H}_{\text {amide }}\right), 3071\left(\mathrm{C}-\mathrm{H}_{\text {arom }}\right), 1654\left(\mathrm{C}=\mathrm{O}_{\text {ketone }}\right)$, $1623\left(\mathrm{C}=\mathrm{O}_{\text {amide }}\right)$; HRMS-ESI $(\mathrm{m} / \mathrm{z})$ : found for $\mathrm{C}_{18} \mathrm{H}_{15} \mathrm{ClN}_{2} \mathrm{O}_{4}[\mathrm{M}+\mathrm{H}]^{+}: 359.0793$.

\subsection{Instrumental Parameters for HPLC}

The HPLC analysis of the active 4-oxoquinoline-3-carboxamide derivatives $\mathbf{1 6 b}$ and $\mathbf{1 7} \mathbf{b}$ was carried out by injecting $20 \mu \mathrm{L}$ of a $25.6 \mu \mathrm{mol} \cdot \mathrm{L}^{-1}$ standard solution of $\mathbf{1 6 b}$ and $21.7 \mu \mathrm{mol} \cdot \mathrm{L}^{-1}$ standard solution of $\mathbf{1 7 b}$, using acetonitrile as mobile phase pumped at a flow rate of $1 \mathrm{~mL} \cdot \mathrm{min}^{-1}$. The temperature of the column was set at $20^{\circ} \mathrm{C}$ (see Supporting Information).

\subsection{Molecular Docking Studies}

Docking studies were performed using the GOLD program on a Windows-based PC. The three-dimensional structure of $\mathbf{1 6 b}$ and $\mathbf{1 7 b}$ were built and minimized to the PM6 level on the molecular modeling program Spartan'10 (Wavefunction Inc., Irvine, CA, USA). The coordinates of 
the protein crystal structure were obtained from the Protein Data Bank (PDB code 3QX3). The ligand etoposide and solvent molecules were removed. Hydrogen atoms were added, and non-hydrogen atoms were merged with the polar respective carbon atoms. Taking the prepared protein and ligand, GOLD docking calculations were performed using standard parameters. The scoring function used during GOLD docking was Goldscore. For each of the 100 independent genetic algorithm (GA) runs, with a selection pressure of $1.1,10.000 \mathrm{GA}$ operations were performed on a set of five islands with a population size of 100 individuals. Default operator weights were used for crossover, mutation, and migration of 95, 95, and 10, respectively. To expedite the calculations, the GA docking was terminated when the top three solutions were within 1.5 $\AA$ RMSD. All other values were set to the default $[31,32]$. Finally, eighty top ranked positions (or conformations) were saved.

\subsection{DNA Relaxation Assay}

Human topoisomerase II $\alpha$ (TopoII $\alpha$ ) was obtained from TopoGEN, Inc. (Columbus, OH, USA). Proteinase $\mathrm{K}$ from Tritirachium album was obtained from Sigma-Aldrich, Inc. (St. Louis, MO, USA) and was dissolved in DNase free water. A TAE gel electrophoresis buffer was used in this assay.

The inhibitory effects of the derivatives on human TopoII $\alpha$ were measured using a Eukaryotic Topoisomerase II Drug Screening Kit (TopoGEN, Inc.). All derivatives were dissolved in DMSO immediately prior to testing.

The substances were tested at a fixed concentration of $0.1 \mathrm{mM}$. This assay concentration was chosen based on the effective concentration of the VP-16 (etoposide) standard $(0.1 \mathrm{mM})$, as recommended by the kit manufacturer (TopoGen). To ensure that DMSO did not interfere in the experiment, different concentrations of DMSO were tested. There was no interference in enzyme function with concentrations from 0\%-5\% DMSO. Supercoiled plasmid DNA (pRYG, $200 \mathrm{ng}$ ) was incubated with human TopoII $\alpha(10 \mathrm{U})$ at $37^{\circ} \mathrm{C}$ for $30 \mathrm{~min}$ in relaxation buffers in the absence or presence of derivatives (final volume is $20 \mu \mathrm{L}$ ). The order of reagent addition was buffer, test derivative, Topo II $\alpha$ and finally DNA.

The assay samples were analyzed by electrophoresis on a $1 \%$ agarose gel without EtdBr $(25 \mathrm{~V}, 18 \mathrm{~h}$, room temperature) in TAE buffer, followed by staining in $0.5 \mu \mathrm{g} / \mathrm{mL}$ of EtdBr to allow for observation of the DNA bands under UV light.

\subsection{In Silico Pharmacokinetics and Toxicity Analysis}

For this analysis, we used Osiris Property Explorer [33] to predict the physicochemical properties (cLogP, solubility), toxicity and "druglikeness" of the most actives derivatives, $\mathbf{1 6 b}$ and $\mathbf{1 7 b}$. Values of "druglikeness" are based on the frequency of occurrence of each fragment of the molecule in commercial drugs, and the drug score evaluates the derivative's potential to qualify as a drug and is related to topological descriptors, fingerprints of molecular "druglikeness", structural keys and other properties such as cLog $\mathrm{P}, \log \mathrm{S}$ and molecular weight. 


\subsection{Anticancer Assays}

\subsubsection{Cytotoxicity against Cancer Cell Lines}

The 4-oxoquinoline-3-carboxamide derivatives $(0.3125-20 \mu \mathrm{M})$ were tested for cytotoxic activity against three cancer cell lines: HCT-116 (colon), ACP03 (gastric), and MDAMB-231 (breast) (Table 1). Active derivatives were also tested against a normal fibroblast cell line (MRC-5). All cell lines were maintained in DMEM medium supplemented with $10 \%$ fetal bovine serum, $2 \mathrm{mM}$ glutamine, $100 \mathrm{U} / \mathrm{mL}$ penicillin, and $100 \mu \mathrm{g} / \mathrm{mL}$ streptomycin and were incubated at $37{ }^{\circ} \mathrm{C}$ with $5 \% \mathrm{CO}_{2}$. Each derivative was dissolved with DMSO to a concentration of $10 \mathrm{mM}$. The final concentration of DMSO in the culture medium was kept at a constant value below $0.1 \%(v / v)$. The derivatives $(0.3125-20 \mu \mathrm{M})$ were incubated with the cells for $72 \mathrm{~h}$. The negative control contained the same amount of DMSO $(0.001 \%$ maximum). Cell viability was determined by the reduction of the yellow dye 3-(4,5-dimethyl2-thiazol)-2,5-diphenyl-2 $H$-tetrazolium bromide (MTT) to a blue formazan product as described by Mosmann [34].

\subsubsection{Cell Membrane Disruption}

The assay was performed in 96 -well plates using a $2 \%$ mouse erythrocyte suspension in $0.85 \%$ $\mathrm{NaCl}$ containing $10 \mathrm{mM} \mathrm{CaCl}_{2}$. Derivatives 10-18, diluted as described above, were tested at $250 \mu \mathrm{g} / \mathrm{mL}$. After incubation at room temperature for $1 \mathrm{~h}$ and centrifugation, the supernatant was removed, and the liberated hemoglobin was measured spectrophotometrically at $540 \mathrm{~nm}$. DMSO was used as a negative control, and Triton X-100 (1\%) was used as a positive control.

\subsubsection{Analysis of the Results}

In the MTT experiments, the results were analyzed according to their means and standard errors in the program GraphPad Prism. Each sample was analyzed in triplicate.

\section{Conclusions}

In this work, we synthesized a new series of 4-oxoquinoline derivatives that exhibited significant antitumor activity against gastric cancer cells. In vitro studies showed that the mechanism of action of $\mathbf{1 6} \mathbf{b}$ is related to topoisomerase II inhibition, which was corroborated by in silico studies. $\mathbf{1 6 b}$ and $\mathbf{1 7 b}$ were more selective to cancer cells compared to doxorubicin, and these results may contribute to the design of novel anticancer derivatives with fewer side effects.

\section{Supplementary Materials}

Supplementary materials can be accessed at: http://www.mdpi.com/1420-3049/19/5/6651/s1.

\section{Acknowledgments}

We acknowledge FAPERJ, CNPQ, CAPES, and UFF for financial support and fellowships. 


\section{Author Contributions}

Luana da S. M. Forez: Synthetic work, discussion of results, writing of the manuscript; Nathalia M. C. Tolentino: Synthetic work; Alessandra M. T. de Souza: Molecular docking validation and In Silico Pharmacokinetic Analysis; Helena C. Castro: Molecular docking, discussion of results, writting of the manuscript; Raquel C. Montenegro: Biological experiments, discussion of results, writing of the manuscript; Rafael F. Dantas: Execution and analysis of Topoisomerase assay results; Maria E. I. M. Oliveira: Execution of Topoisomerase assays; Floriano P. Silva, Jr.: Responsible for the experimental design and analysis of Topoisomerase assay results; Leilane H. Barreto: Cytotoxic experiments; Rommel M. R. Burbano: Biological experiments and writing of the manuscript; Bárbara AbrahimVieira: Molecular Docking and analysis of $\mathbf{1 7 b}$ at topoisomerase II; Riethe de Oliveira: Molecular Docking and analysis of $\mathbf{1 6 b}$ at topoisomerase II; Vitor F. Ferreira: Planning, synthetic work, discussion of results and conclusions, writing of the manuscript; Anna C. Cunha: Planning, synthetic work, discussion of results and conclusions, writing of the manuscript; Fernanda da C. S. Boechat: Planning, synthetic work, discussion of results and conclusions, writing of the manuscript; Maria Cecília B. V. de Souza: Planning, synthetic work, discussion of results and conclusions, writing of the manuscript.

\section{Conflicts of Interest}

The authors declare no conflict of interest.

\section{References and Notes}

1. Suthar, S.K.; Jaiswal, W.; Lohan, S.; Bansal, S.; Chaudhary, A.; Tiwari, A.; Alex, A.T.; Joesph, A. Novel quinolone substituted thiazolidin-4-ones as anti-inflammatory, anticancer agents: Design, synthesis and biological screening. Eur. J. Med. Chem. 2013, 63, 589-602.

2. Mitscher, L.A. Bacterial topoisomerase inhibitors: Quinolone and pyridone antibacterial agents. Chem. Rev. 2005, 105, 559-592.

3. Ahmed, A.; Daneshtalab, M. Nonclassical Biological Activities of Quinolone Derivatives. J. Pharm. Pharm. Sci. 2012, 15, 52-72.

4. Mugnaini, C.; Pasquini, S.; Corelli, F. The 4-quinolone-3-carboxylic acid motif as a multivalent Scaffold in Medicinal Chemistry. Curr. Med. Chem. 2009, 16, 1746-1767.

5. Audisio, D.; Messaoudi, S.; Peyrat, J.F.; Brion, J.D.; Alami, M.J. A general copper powder-catalyzed ullmann-type reaction of 3-halo-4(1H)-quinolones with variousnitrogen-containingnucleophiles. J. Org. Chem. 2011, 76, 4995-5005.

6. Xia, Y.; Yang, Z.; Xia, P.; Hackl, T.; Hamel, E.; Mauger, A.; Wu, J.; Lee, K. Antitumor agents. 211. Fluorinated 2-phenyl-4-quinolone derivatives as antimitotic antitumor agents. J. Med. Chem. 2001, 44, 3932-3936.

7. Abbas, J.A.; Stuart, R.K. Vosaroxin: A novel antineoplasic quinolone. Expert Opin. Investig. Drugs 2012, 21, 1223-1233. 
8. Advani, R.H.; Hurwitz, H.I.; Gordon, M.S.; Ebbinghaus, S.W.; Mendelson, D.S.; Wakelee, H.A. Voreloxin, a first-in-class anticancer quinolone derivative, in relapsed/refractory solid tumors: A report on two dosing schedules. Clin. Cancer Res. 2010, 16, 2167-2175.

9. Lai, Y.; Huang, L.; Lee, K.; Xiao, Z.; Bastow, K.F.; Yamiri, T.; Kuo, S. Synthesis and biological relationships of 3',6-substituted 2-phenyl-4-quinolone-3-carboxylic acid derivatives as antimitotic agents. Bioorg. Med. Chem. 2005, 13, 265-275.

10. Rajabalian, S.; Foroumadi, A.; Shafiee, A.; Emami, A. Functionalized N-(2-oxyiminoethyl) piperazinyl quinolones as new cytotoxic agents. J. Pharm. Pharm. Sci. 2007, 10, 153-158.

11. Abe, H.; Kawada, M.; Inoue, H.; Ohba, S.; Nomoto, A.; Watanabe, T.; Shibasaki, M. Synthesis of intervenolin, an antitumor natural quinolone with unusual substituents. Org. Lett. 2013, 15, 2124-2127.

12. Hawtin, R.E.; Stockett, D.E.; Byl, J.A.W.; Mcdowell, R.S.; Tan, N.; Arkin, M.R. Structural biology of human H3K9 methyltransferases. PLoS One 2010, 5, e8570.

13. Foroumadi, A.; Emami, S.; Rajabalian, S.; Badinloo, M.; Mohammdhosseini, N.; Shafiee, A. N-Substituted piperazinyl quinolones as potential cytotoxic agents: Structure-activity relationships study. Biomed. Pharmacother. 2009, 63, 216-220.

14. Chen, Y.; Chung, C.; Chen, I.; Chen, P.; Jeng, H. Synthesis and cytotoxic activity evaluation of indolo-, pyrrolo-, and benzofuro-quinolin-2(1H)-ones and 6-anilinoindoloquinoline derivatives. Bioorg. Med. Chem. 2002, 10, 2705-2712.

15. Sabbah, D.; Simms, N.; Wang, W.; Dong, Y.; Ezell, E.L.; Brattain, M.G.; Vennerstrom, J.L.; Zhong, H.A. N-Phenyl-4-hydroxy-2-quinolone-3-carboxamides as selective inhibitors of mutant H1047R phosphoinositide-3-kinase (PI3Ka). Bioorg. Med. Chem. 2012, 20, 7175-7183.

16. Voreloxin is not in the market (but in clinical trial) and literature still ask about its ability of replacing the anthracycline drugs, requesting future investigation to confirm its efficacy. Altogether these data point doxorubicin as the best control drug to compare our active experimental profile against cancer cell lines, see: Freeman, C.; Keane, N.; Swords, R.; Giles, F. Vosaroxin: A new valuable tool with the potential to replace anthracyclines in the treatment of AML? Expert Opin. Pharmacother. 2013, 14, 1417-1427.

17. Gould, R.G.; Jacobs, W.A. The Synthesis of Certain Substituted Quinolines and 5,6-Benzoquinolines. J. Am. Chem. Soc. 1939, 61, 2890-2895.

18. Snyder, H.R.; Freier, H.E.; Kovacic, P.; Heyningen, E.M.V. Synthesis of 4-hydroxyquinolines. VIII. Some halogen containing 4-aminoquinoline derivatives. J. Am. Chem. Soc. 1947, 69, 371-373.

19. Stern, E.; Muccioli, G.G.; Millet, R.; Goossens, J.-F.; Farce, A.; Chavatte, P.; Poupaert, J.H.; Lambert, D.M.; Depreux, P.; Hénichart, J.-P. Novel 4-oxo-1,4-dihydroquinoline-3-carboxamide derivatives as new CB2 cannabinoid receptors agonists: Synthesis, pharmacological properties, and molecular modeling. J. Med. Chem. 2006, 49, 70-79.

20. Riegel, B.; Lappin, G.R.; Adelson, B.H.; Jackson, R.I.; Albisetti C.J., Jr.; Dodson, R.M.; Baker, R.H. The synthesis of some 4-quinolinols and 4-chloroquinolines by the ethoxymethylenemalonic ester method. J. Am. Chem. Soc. 1946, 68, 1264-1266.

21. Matta, A.D.; Bernardino, A.M.R.; Romeiro, G.A.; Oliveira, M.R.P.; Souza, M.C.B.V.; Ferreira, V.F. Nucleosides having quinolone derivatives as nitrogenated base: Regiospecific and stereospecific 
ribosylation of 3-carbethoxy-1,4-dihydro-4-oxoquinolines. Nucleos. Nucleot. Nucleic Acids 1996, $15,889-898$.

22. Doxorubicin is one of the most important anticancer chemotherapeutic drug currently in use. Importantly, despite of its side effects, it is still in use and new formulations options are still being investigated due to its significant therapeutic profile, see: Deepa, K.; Singha, S.; Panda, T.J. doxorubicin nanoconjugates. Nanosci. Nanotechnol. 2014, 14, 892-904.

23. Wu, C.C.; Li, T.K.; Farh, L.; Lin, L.Y.; Lin, T.S.; Yu, Y.J.; Yen, T.J.; Chiang, C.W.; Chan, N.L. Structural basis of type II topoisomerase inhibition by the anticancer drug etoposide. Science 2011, 333, 459-462.

24. Esteves-Souza, A.; Rodrigues-Santos, C.E.; del Cistia, C.N.; Silva, D.R.; Sant'anna, C.M.R.; Echevarria, A. Solvent-free synthesis, DNA-topoisomerase II activity and molecular docking study of new asymmetrically $N, N^{\prime}$-substituted ureas. Molecules 2012, 17, 12882-12894.

25. Lipinski, C.A. Lead- and drug-like compounds: The rule-of-five revolution. Drug Discov. Today Technol. 2004, 4, 337-341.

26. Gajbhiye, A.; Chaturvedi, L. Synthesis of 4-quinolones derivatives for their antihistaminic activity. Int. J. Pharm. Pharm. Sci. 2013, 5, 223-227.

27. Shah, K.J.; Coats, E.A. Design, synthesis, and correlation analysis of 7-Substituted4hydroxyquinoline-3-carboxylic acids as inhibitors of cellular respiration. J. Med. Chem. 1977, 20, 1001-1006.

28. Wathen, L.K.; Wathen, L.M. Method of Preventing or Treating Atherosclerosis or Restenosis. U.S. Patent WO2004019932 (A1), 11 March 2004.

29. Sheth, U.; Fanning, T.T.D.; Numa, M.; Binch, H.; Hurley, D.J.; Zhou, J.; Hadida, R.S.S.; Hazlewood, A.R.; Silina, A.; Vairagoundar, R.; et al. 4-Oxo-1H-Quinoline-3-Carboxamides as Modulators of ATP-Binding Cassette Transporters. U.S. Patent WO2011072241 (A9), 16 June 2011.

30. Singh, A.; van Goor, F.; Worley, L.J.F.; Jennings, F.; Knapp, T. Compounds Useful in Cftr Assays and Methods Therewith. U.S. Patent WO 2007075946 (A1), 5 July 2007.

31. Verdonk, M.L.; Berdini, V.; Hartshorn, M.L.; Mooij, W.T.; Murray, C.W.; Taylor, R.D.; Watson, P. Virtual screening using protein-ligand docking: Avoiding artificial enrichment. J. Chem. Inf. Comput. Sci. 2004, 44, 793-806.

32. Verdonk, M.L.; Cole, J.C.; Hartshorn, M.J.; Murray, C.W.; Taylor, R.D. Improved protein-ligand docking using GOLD. Proteins: Struct. Funct. Genet. 2003, 52, 609-623.

33. Sander, T. Actelion Pharmaceuticals Ltd. Available online: http://www.organic-chemistry.org/ (accessed on 13 May 2014).

34. Mosmann, T. Rapid colorimetric assay for cellular growth and survival: Application to proliferation and cytotoxicity assays. J. Immunol. Methods 1983, 65, 55-63.

Sample Availability: Samples of the compounds 10-18 are available from the authors.

(C) 2014 by the authors; licensee MDPI, Basel, Switzerland. This article is an open access article distributed under the terms and conditions of the Creative Commons Attribution license (http://creativecommons.org/licenses/by/3.0/). 